\title{
The 2018 fire season in North America as seen by TROPOMI: aerosol layer height intercomparisons and evaluation of model-derived plume heights
}

\author{
Debora Griffin $^{1}$, Christopher Sioris ${ }^{1}$, Jack Chen $^{1}$, Nolan Dickson ${ }^{1,2}$, Andrew Kovachik ${ }^{1,2}$, Martin de Graaf ${ }^{3}$, \\ Swadhin Nanda $^{4}$, Pepijn Veefkind ${ }^{3,4}$, Enrico Dammers ${ }^{1}$, Chris A. McLinden ${ }^{1}$, Paul Makar ${ }^{1}$, and Ayodeji Akingunola ${ }^{1}$ \\ ${ }^{1}$ Air Quality Research Division, Environment and Climate Change Canada, Toronto, Ontario, Canada \\ ${ }^{2}$ Department of Physics and Astronomy, University of Waterloo, Waterloo, Ontario, Canada \\ ${ }^{3}$ Royal Netherlands Meteorological Institute (KNMI), De Bilt, the Netherlands \\ ${ }^{4}$ Geoscience and Remote Sensing, Delft University of Technology, Delft, the Netherlands
}

Correspondence: Debora Griffin (debora.griffin@canada.ca)

Received: 29 October 2019 - Discussion started: 8 November 2019

Revised: 10 February 2020 - Accepted: 15 February 2020 - Published: 30 March 2020

\begin{abstract}
Before the launch of the TROPOspheric Monitoring Instrument (TROPOMI), only two other satellite instruments were able to observe aerosol plume heights globally, the Multi-angle Imaging SpectroRadiometer (MISR) and Cloud-Aerosol Lidar with Orthogonal Polarization (CALIOP). The TROPOMI aerosol layer height is a potential game changer, since it has daily global coverage, and the aerosol layer height retrieval is available in near real time. The aerosol layer height can be useful for aviation and air quality alerts, as well as for improving air quality forecasting related to wildfires. Here, TROPOMI's aerosol layer height product is evaluated with MISR and CALIOP observations for wildfire plumes in North America for the 2018 fire season (June to August). Further, observing system simulation experiments were performed to interpret the fundamental differences between the different products. The results show that MISR and TROPOMI are, in theory, very close for aerosol profiles with single plumes. For more complex profiles with multiple plumes, however, different plume heights are retrieved; the MISR plume height represents the top layer, and the plume height retrieved with TROPOMI tends to have an average altitude of several plume layers.

The comparison between TROPOMI and MISR plume heights shows that, on average, the TROPOMI aerosol layer heights are lower, by approximately $600 \mathrm{~m}$, compared to MISR, which is likely due to the different measurement techniques. From the comparison to CALIOP, our results show
\end{abstract}

that the TROPOMI aerosol layer height is more accurate over dark surfaces, for thicker plumes, and plumes between approximately 1 and $4.5 \mathrm{~km}$.

MISR and TROPOMI are further used to evaluate the plume height of Environment and Climate Change Canada's operational forecasting system FireWork with fire plume injection height estimates from the Canadian Forest Fire Emissions Prediction System (CFFEPS). The modelled plume heights are similar compared to the satellite observations but tend to be slightly higher with average differences of 270 580 and $60-320 \mathrm{~m}$ compared to TROPOMI and MISR, respectively.

\section{Introduction}

Wildfires are a significant source of air pollution, which can adversely impact the air quality in populated areas (e.g. Landis et al., 2018; Meng et al., 2019). In recent years fire behaviour has also become more aggressive in North America due to increased temperatures, drought, high fuel loading and tree death (e.g. Kitzberger et al., 2007; Littell et al., 2009; Westerling, 2016). As such, the number and size of wildfires have been shown to increase with larger areas being burned (e.g. Landis et al., 2018). Wildfires emit fine particulate matter $\left(\mathrm{PM}_{2.5}\right)$ and trace gases, including nitrogen oxides $\left(\mathrm{NO}_{x}\right)$, carbon monoxide $(\mathrm{CO})$, and ammonia $\left(\mathrm{NH}_{3}\right)$ (Akagi et al., 
2011; Andreae, 2019, and references therein). These traces and aerosols negatively impact air quality and are all harmful to people and their environment (e.g. Anenberg et al., 2018; Schraufnagel et al., 2019). The amounts released during the fire are highly variable and depend on the fuel type and intensity of the fire. Due to the nature of wildfires with plume heights reaching several kilometres, aerosol plumes produced by wildfires can be transported over vast distances (e.g. Damoah et al., 2004; Derwent et al., 2004; Duck et al., 2007; Lutsch et al., 2016, 2019). Plumes from larger fires can thus cause aviation hazards and affect regional air quality thousands of kilometres away from the source and even across continents (e.g. Colarco et al., 2004; Jaffe et al., 2004; Teakles et al., 2017).

With the increased fire intensity and number of fires, there is an increased necessity for modelling and forecasting smoke impacts from wildfires to be able to accurately predict the concentration of harmful pollutants and to issue necessary alerts on time (e.g. Yue et al., 2015). The height of the smoke plumes has a large influence on where these pollutants are being transported. Thus, an extremely important component in predicting the air quality due to wildfires is to have a good understanding of the plume height and plume rise from wildfires. If the plume height and plume rise are not adequately simulated, the transport of pollutants, thus the final surface-level $\mathrm{PM}_{2.5}$ concentration, will be incorrectly modelled.

Experimentally, plume height can be measured from the ground, aircraft and space. Satellite measurements of plume heights have the advantage of superior coverage in comparison to ground-based and aircraft-borne measurements. As such, satellite-remote sensing measurements are an essential tool in observing the plume heights from wildfires. So far only two satellite instruments, namely the Multiangle Imaging SpectroRadiometer (MISR; Diner et al., 1999) and the Cloud-Aerosol Lidar with Orthogonal Polarization (CALIOP; Winker et al., 2003), were able to observe the altitude of smoke plumes on a global scale. The time of observation and method used to determine the height of the plume are very different for these two instruments, making them complementary. Because the observation methods are different, it is important to understand and quantify the differences in the plume height retrievals. MISR observes every scene from nine different angles, which are then used to estimate the height of the plume. CALIOP is an active lidar instrument, which can provide very detailed vertical profiles of clouds and aerosols and can observe optically thin plumes. However, these two instruments have the disadvantage of very limited coverage where most fires are missed (Diner et al., 1999; Winker et al., 2007, 2003); MISR provides global coverage about once per week ( $8 \mathrm{~d}$ near the Equator and every $2 \mathrm{~d}$ near the poles), and CALIPSO provides global coverage about every $16 \mathrm{~d}$. The recently launched Tropospheric Monitoring Instrument (TROPOMI) can potentially fill this gap due to its daily global coverage combined with its relatively high spatial resolution. TROPOMI is a passive sensor that provides daily global coverage. TROPOMI has a new product that is dedicated to retrieval of the height of tropospheric aerosols. The TROPOMI aerosol layer height product utilizes a very different method to than those used for MISR or CALIOP; the TROPOMI algorithm estimates the plume height based on the absorption by oxygen $\left(\mathrm{O}_{2}\right)$ in the $A$ band between 759 and $770 \mathrm{~nm}$. A similar approach has been applied to the measurements from the Earth Polychromatic Imaging Camera (EPIC) on DSCOVR (Deep Space Climate Observatory) (Xu et al., 2017, 2019); however, this product is currently not operational, and only a number of case studies are available. Very recently another plume height product has been created from MODIS observations, utilizing a thermal contrast technique (Lyapustin et al., 2019). These estimates are available globally; however, they are limited to plume heights near thermal hotspots.

Some studies have compared MISR and CALIOP plume heights, but very few coincident overpasses exist over fires, and the time difference of approximately $2 \mathrm{~h}$ can create additional challenges for comparing the plume heights, as the fire is expected to increase in intensity throughout the morning, with the peak fire activity being in the early afternoon, and changes in the planetary boundary layer tend to be higher later in the afternoon (Kahn et al., 2008; Tosca et al., 2011; Gonzalez-Alonso et al., 2019). CALIOP and (standard) MISR plume heights have also been validated with ground-based lidars (e.g. Moroney et al., 2002; Naud et al., 2004; Kim et al., 2008; Tao et al., 2008).

In this study, the TROPOMI aerosol layer height is evaluated for the first time with MISR and CALIOP. The aerosol layer height from three satellite instruments (MISR, CALIOP, and TROPOMI) that can measure the plume height are compared for the 2018 fire season (June-August) in North America. Finally, we also compare the satellite observed plume heights to those from Environment and Climate Change Canada's (ECCC) air quality forecast modelling system, namely FireWork, with smoke plume injection heights based on the Canadian Forest Fire Emissions Prediction System (CFFEPS).

This paper is organized as follows. In Sect. 2, the three different satellite-borne instruments and the air quality model are described. Section 3 describes the effect of the different measurement techniques of the satellites on the plume height estimate solely using modelled aerosol profiles. The intercomparison of the plume height observations of the three satellites and the modelled plume height are discussed in Sects. 4 and 5, respectively. A summary and conclusions are provided in Sect. 6. 


\section{Datasets}

\section{$2.1 \quad$ TROPOMI}

TROPOMI is the single payload on the Copernicus Sentinel5P satellite that was launched on 13 October 2017. The satellite has near-full-surface coverage on a daily basis with a local overpass time of around 13:30 (Veefkind et al., 2012). The instrument has four spectrometers; three that cover the ultraviolet-near infrared (UV-NIR) with two spectral bands at $270-500$ and $675-775 \mathrm{~nm}$, and there is one for the shortwave infrared (SWIR). The spatial resolution of TROPOMI varies with across-track position and is between $3.6 \mathrm{~km} \times$ $7.2 \mathrm{~km}$ (in UV-NIR) and $7.2 \mathrm{~km} \times 7.1 \mathrm{~km}$ (SWIR). As of 6 August 2019, the along-track sampling has been improved to $5.6 \mathrm{~km}$.

The TROPOMI Aerosol Layer Height (AER_LH) algorithm was developed by the Royal Netherlands Meteorological Institute (KNMI) and utilizes the absorption in the oxygen $A$ band of the spectrum between 759 and $770 \mathrm{~nm}$ (Sanders and de Haan, 2016). The oxygen $A$ band is a highly structured line absorption spectrum with strongest absorption lines occurring between 760 and $761 \mathrm{~nm}$. An aerosol layer aloft will decrease the photon path of the backscattered solar radiation, due to scattering by the aerosol layer, compared to backscattered radiation in a similar scene without the aerosol layer. This decreases the depths of the absorption lines in the oxygen $A$ band of the measurements of the scene with the aerosol layer. The aerosol layer mid-height is estimated from a fit of the measurements to a simplified, single aerosol layer model simulation of the oxygen $A$-band reflectance, using an optimal estimation scheme, under cloud-free conditions. The final height reported is the difference between top pressure and bottom pressure of the assumed uniform scattering layer with a constant thickness of $50 \mathrm{hPa}$. The vertical data resolution is continuous, and values for the aerosol layer height (ALH) range from 1050 to $75 \mathrm{hPa}$. A more detailed description of the TROPOMI aerosol layer height product can be found in Nanda et al. (2019) and Sanders and de Haan (2016). Due to the importance of the backscatter signal in the retrieval, which can be dominated by the surface reflectance in case of bright surfaces and thin aerosol layers, the aerosol layer height is expected to be more robust over dark surfaces such as sea and oceans (Sanders and de Haan, 2016).

The aerosol layer height can give insight into the height of aerosols in the free troposphere of plumes from wildfires, volcanoes and desert dust. This product could supply important information in a timely manner on aerosol location and transport of wildfire plumes for the purpose of air quality forecasting and aviation safety.

There are two versions available for the TROPOMI aerosol layer height; the near-real-time (NRTI) product is available approximately $3 \mathrm{~h}$ after the satellite overpass, and the offline (OFFL) product is available approximately 2 weeks after the satellite overpass. The algorithm for the NRTI and OFFL product is the same; however, not all products needed for the retrieval are available in NRTI. Therefore, differences between the NRTI and OFFL products include the following:

- In NRTI the Visible Infrared Imaging Radiometer Suite (VIIRS) cloud mask is not available, and a cloud mask is constructed from the FRESCO cloud product, brightness thresholds, and scene homogeneity.

- In the OFFL product a different solar irradiance spectrum may be used (if a future irradiance spectrum is closer to the radiance measurement). This should not change the results much.

In general, the OFFL product should perform better and is a better choice if timeliness is not an issue. Here, we evaluate the OFFL version only, as the NRTI version was not available for the time period that we investigated. As a first indication, the quality of each successful ALH retrieval is indicated by a quality assurance value (qa_value). If the input data or measurement configuration becomes close to a predefined limit, first the qa_value is lowered, if another limit is crossed, the pixel is filtered. For example all pixels with a solar zenith angle (SZA) below $60^{\circ}$ should have a good quality retrieval. However, for SZA $>60^{\circ}$ the curvature of the Earth and the long photon path through the atmosphere may compromise a good retrieval. Above $75^{\circ}$, no retrievals are attempted. However, for $60^{\circ}<\mathrm{SZA}<75^{\circ}$ the retrieval is performed, but the qa_values are lowered to $20 \%$, to indicate to the user to use caution. This is done for all pixels with a (small) cloud fraction (qa lowered to $50 \%$ ), small absorbing aerosol index (AAI) (50\%), high surface roughness $(50 \%)$, and within sunglint and south Atlantic anomaly regions $(50 \%)$. Apart from the quantitative layer height, the quality flag provided alongside can be useful by itself, e.g. to locate and identify the presence of aerosol plumes and its vertical shape.

\subsection{MISR}

The Multi-angle Imaging SpectroRadiometer (MISR) instrument is on NASA's Terra spacecraft that has been in orbit since 1999. MISR has nine fixed push-broom cameras and views every scene from nine different angles. Each of these cameras has four line-array charge-coupled devices (CCDs) covering spectral bands centred at 446, 558, 672, and $867 \mathrm{~nm}$. Its highest spatial sampling is $275 \mathrm{~m}$ at all angles. This design allows it to measure the height of smoke plumes using stereoscopic techniques (Muller et al., 2002; Zakšek et al., 2013; Fisher et al., 2014; Val Martin et al., 2018). The height retrieval from MISR is not impacted by bright surfaces (Moroney et al., 2002; Muller et al., 2002). MISR has approximately three overpasses daily over North America at around 10:30 a.m. local time, with a swath width of approximately $360 \mathrm{~km}$.

An operational MISR cloud top product is available; however, the operational algorithm uses fixed parameters that 
are applied to all scenes equally (Muller et al., 2002; Nelson et al., 2013). Instead, the plume height used here is not a standard product of MISR, and we used the visualization and analysis program called the MISR INteractive eXplorer (MINX) tool to retrieve the plume heights (Nelson et al., 2008, 2013). This tool takes advantage of wind-direction information inherent in smoke plumes from active fires in order to determine plume heights and wind speeds at higher resolution and with greater accuracy than provided by the standardoperational MISR product (Kahn et al., 2007). MINX is an interactive visualization and analysis program written in IDL and designed to make MISR data more accessible to science users. Its principal use is to retrieve heights and motion for aerosol plumes and clouds using stereoscopic methods. Within MINX, each plume has to be processed individually and plume shapes have to be digitized manually. Moderate Resolution Imaging Spectroradiometer (MODIS) brightness temperature anomalies are used to help locate the fire plumes, and plume heights are retrieved for smoke plumes close to the fire hotspots. The red-band data have a higher horizontal resolution $(275 \mathrm{~m})$; however, where contrast is poor within plume features and between the plume and the surface, blueband retrievals provide better results at $1.1 \mathrm{~km}$ resolution (Val Martin et al., 2018). In this study, we used the blue-band results with "good" and "fair" quality flags. Further details can be found in Kahn et al. (2007); Val Martin et al. (2010); Nelson et al. (2013). Limitations of the MISR instrument include the following: (1) the narrow MISR swath limits the frequency of global coverage; thus many smoke plumes can be missed; (2) the overpass time of around 10:30 LT precedes the daytime peak in fire activity.

The MODIS thermal anomaly product (MOD14) (Giglio et al., 2003, 2006, 2016) is used here to locate the wildfires. We searched for clusters of thermal anomalies with a confidence of at least $75 \%$ and a minimum summed fire radiative power (FRP) (within a $5 \mathrm{~km}$ radius) of at least 1000 . These locations were then used to search for plumes using the MINX package. There are currently two MODIS instruments in space, on NASA's Terra and Aqua satellites. Daytime measurements of Terra and Aqua are around 10:30 and 13:30 local time, respectively. For the MINX analysis, we utilized the thermal anomalies from MODIS Terra. Note that fires can potentially be missed for several reasons, including when there is cloud cover, when it is under thick smoke plumes and if the FRP signal is too low (e.g. small fires).

\subsection{CALIOP}

CALIOP, part of the Cloud-Aerosol Lidar and Infrared Pathfinder Satellite Observation (CALIPSO) satellite that was launched in 2006, is a two-wavelength (532 and $1064 \mathrm{~nm}$ ) polarization-sensitive lidar. CALIOP can provide high-resolution vertical profiles of aerosols and clouds, as well as their optical properties (Winker et al., 2003, 2007). It is an active satellite instrument, sensing pulses of light at 532 and $1064 \mathrm{~nm}$. The backscattered return is measured through a $1 \mathrm{~m}$ telescope that measures the intensities at $1064 \mathrm{~nm}$ and two orientations at $532 \mathrm{~nm}$ (parallel and perpendicular to the polarization plane of the transmitted beam). The vertical resolution of the cloud and aerosol profiles is between 120 and $360 \mathrm{~m}$, and the footprint is $90 \mathrm{~m}$. CALIOP can detect even very thin aerosol layers with an aerosol optical thickness of 0.01 with sufficient averaging (McGill et al., 2007). CALIOP has approximately three overpasses at 01:30 and 13:30 local time over North America and has a very narrow swath width of just a hundred metres. In this study, we use the daytime aerosol layer product v4 (Layer_Top_Altitude and Layer_Base_Altitude) (McGill et al., 2007; Vaughan et al., 2009), which provides the top and base height of aerosol layers detected (between the surface and $30 \mathrm{~km}$ ), averaged over $5 \mathrm{~km}$ along the $100 \mathrm{~m}$ wide swath and filter out all aerosol plumes except those containing smoke or polluted dust (Omar et al., 2009). While CALIOP has excellent vertical resolution and has the ability to resolve the layer heights of multiple plumes in a single profile, its swath width is very narrow and has a $16 \mathrm{~d}$ global coverage.

\subsection{GEM-MACH}

We also make use of the satellite-derived plume heights to evaluate the modelled plume heights from an experimental version of ECCC's FireWork biomass burning air quality forecast modelling system. The core of the FireWork system is the Global Environmental Multiscale-Modelling Air-quality and Chemistry (GEM-MACH) coupled meteorology and chemical transport model. GEM-MACH contains a detailed representation of atmospheric chemistry, including emissions, dispersion, and removal processes of 42 gaseous and eight particle species, which reside within the physics module of the Global Environmental Multiscale (GEM) weather forecast model (Côté et al., 1998; Girard et al., 2014). The operational version of the model (Moran et al., 2010; Pendlebury et al., 2018) has a horizontal resolution of $10 \mathrm{~km} \times 10 \mathrm{~km}$ for the North American domain and 80 vertical levels (from the surface to approximately $0.1 \mathrm{hPa}$ ) on a hybrid pressure grid. The forecast system produces air quality forecast conditions for $48 \mathrm{~h}$ and is initialized every $12 \mathrm{~h}$ at 00:00 and 12:00 UTC.

The experimental GEM-MACH system was used as part of an ensemble of models contributing to the Fire Influence on Regional to Global Environments and Air Quality (FIREXAQ) experiment at a resolution of $2.5 \mathrm{~km}$ - here, the same system was used at $10 \mathrm{~km}$ resolution to simulate forest fire emissions, transformation, and transport for the summer of 2018 (1 June to 31 August 2018), with an internal model physics time step of $7.5 \mathrm{~min}$, and output provided every hour. The outputs for the simulations included $\mathrm{PM}_{2.5}$ fields and estimates of the aerosol optical depth at a variety of wavelengths calculated internally using an online Mie lookup table (Makar et al., 2015a, b). Differences between the op- 
erational and experimental version of GEM-MACH can be found in Table S1 in the Supplement.

Near-real-time fire hotspot information is obtained from the three satellite sensors MODIS, the Advanced Very High Resolution Radiometer (AVHRR) and VIIRS processed through the Canadian Wildland Fire Information System operated by the Canadian Forest Service, Natural Resources Canada (http://cwfis.cfs.nrcan.gc.ca, last access: 1 October 2019; Lee et al., 2002). Hourly fire emissions and smoke plume injection heights were estimated with the CFFEPS module at individual hotspot locations. Fire plume injection height in GEM-MACH is parameterized in the CFFEPS module with hourly modelled meteorology as detailed in Chen et al. (2019). The injection height is determined based on the balance of estimated plume buoyancy and the modelled environmental lapse rate at the fire location. Total heat flux from fire is determined from modelled fuel consumed per area and the heat of combustion of dry wood fuel (Byram, 1959). The fraction of energy that enters the plume for convection is further parameterized based on thermodynamic energy balance, accounting for heat lost to fuel, moisture, radiation, conduction and incomplete combustion. The hourly plume injection height is determined based on the dry adiabatic equilibrium of the buoyant plume and the modelled environmental lapse rate at fire location. Further details describing the implementation of the GEM-MACH wildfire component within the model can be found in e.g. MunozAlpizar et al. (2017), Pavlovic et al. (2016), and Chen et al. (2019).

Previous work with CFFEPSv2.03 (Chen et al., 2019) showed a substantial improvement in forecast skill for daily maximum values of particulate matter, $\mathrm{NO}_{2}$ and $\mathrm{PM}_{2.5}$ relative to the previous ECCC operational forecast, which employed a much simpler Briggs plume rise approach for forest fire emissions plume rise. Here, we investigate how the particulate mass and plume injection height calculated with GEM-MACH and from CFFEPSv4.0 and transported downwind over a short period of time by GEM-MACH near fire hotspot locations compares to satellite-derived plume heights. In order to allow a direct comparison between satellite-derived plume heights and those predicted by GEMMACH/CFFEPSv4.0, the hourly modelled $\mathrm{PM}_{2.5}$ concentrations were interpolated temporally to the satellite overpass times. Only plumes due to fires are investigated; we subtracted the model run without fire emissions from the run with fire emissions to remove $\mathrm{PM}_{2.5}$ contributions from nonfire sources.

\section{Observing system simulation experiments (OSSE)}

The three satellite instruments are fundamentally very different and use three different parts of the radiative spectrum to determine the plume height. Here, we evaluate simulated plume heights from model output using similar techniques as MISR and TROPOMI, respectively, for several modelled aerosol profiles. This will help to interpret the fundamental differences between these retrieval techniques, to confirm whether the satellites are observing the same plume and to evaluate the methodology for the model plume height estimation best suited for comparison to the satellite-derived plume heights. The aerosol profiles used here are 24 modelled profiles (from the GEM-MACH model) containing smoke at various altitudes between approximately 1 and $7 \mathrm{~km}$ with various aerosol optical depths (AODs). Nine example profiles of these 24 are shown in Fig. 1d-1. Note, this section is only using modelled aerosol profiles (no satellite observations were used here) with the aim of evaluating the different retrieval algorithms and understanding what simple plume height definitions can be used to compare the model output to the satellite observations.

\subsection{MISR-OSSE plume heights}

In order to simulate the layer height retrieved by MISR using aerosol profiles from GEM-MACH, we rely on the concept that MISR's layer height is defined as the layer contributing the most to the reflective contrast relative to the surrounding air (Kahn et al., 2007). Thus, to determine the MISR-equivalent plume layer height from the GEM-MACH profiles, we simply calculate the $\mathrm{d} I / \mathrm{d} N_{z}$ weighting function, where $I$ is the $672 \mathrm{~nm}$ monochromatic radiance at the top of the atmosphere for a viewing zenith angle of $26^{\circ}$. $N_{z}$ is the GEM-MACH aerosol number density at altitude $z$, and the weighting function is calculated numerically by perturbing layers of the profile independently and determining the radiance difference relative to the unperturbed case. The $\mathrm{PM}_{2.5}$ aerosol number density vertical profile is obtained from GEM-MACH for these smoke cases. The number density is obtained from the fine-mode mass density profile of the model, assuming a typical mass of a fine-mode particle of $1.55 \times 10^{-9} \mu \mathrm{g}$ based on a particle density of $1.35 \mathrm{~g} \mathrm{~cm}^{-3}$ (Reid and Hobbs, 1998) and assuming spherical particles with a radius of $130 \mathrm{~nm}$. These approximations used here may not necessarily reflect GEM-MACH's predictions for particulate mass, radius or density, but those assumptions have been used to reflect that smoke particles tend to be small and to make the interpretation of the results less complicated by using the same assumptions for each simulated case. The retrieved layer heights will not depend on a multitude of aerosol properties. The VECTOR radiative transfer (RT) model is used (McLinden et al., 2002), and aerosol scattering is simulated using Mie theory. For the Mie calculations, a gamma distribution is used for the aerosol size distribution (Eq. 2.56 of Hansen and Travis, 1974) with an effective radius of $130 \mathrm{~nm}$, an effective variance of $130 \mathrm{~nm}$, and a size range of 0.01 to $260 \mathrm{~nm}$. The complex refractive index, $1.68+0.36 i$, is appropriate for external mixed black carbon at $99 \%$ relative humidity (which is expected near the fire source) (Kou, 1996). Note that this might not reflect the 
(a)
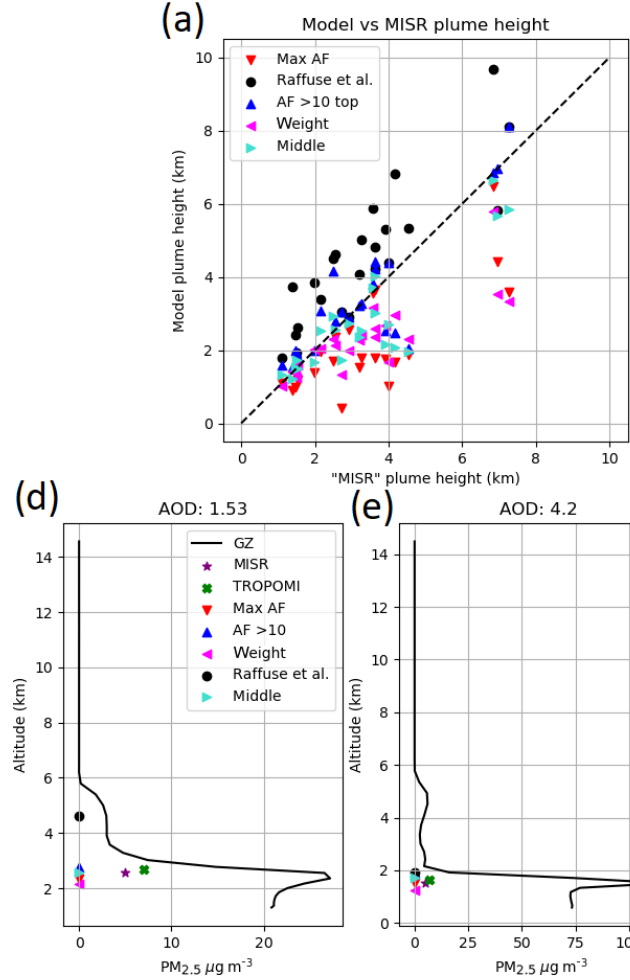

(e)

(e) AOD: 4.2

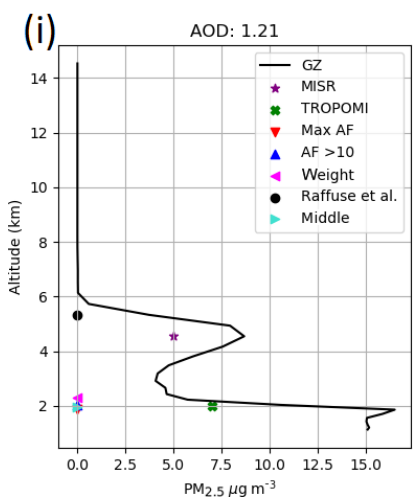

(b)

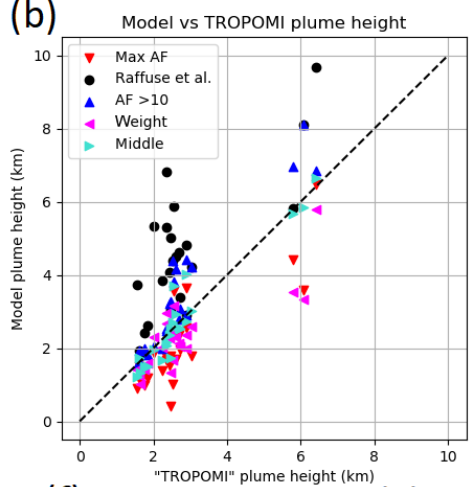

(c)

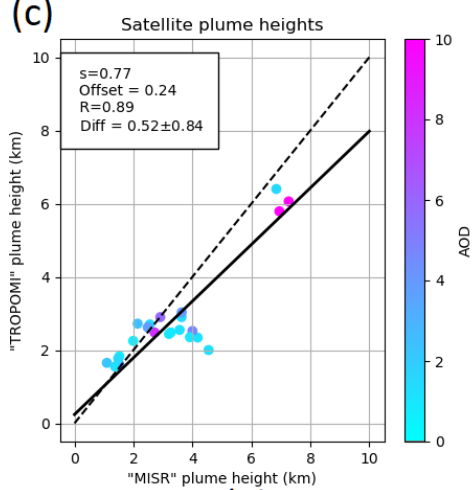

(f)

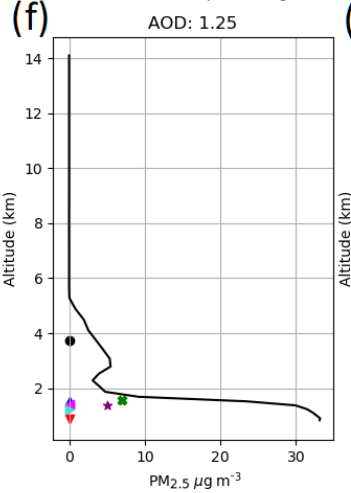

(g) (h) (1)

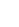
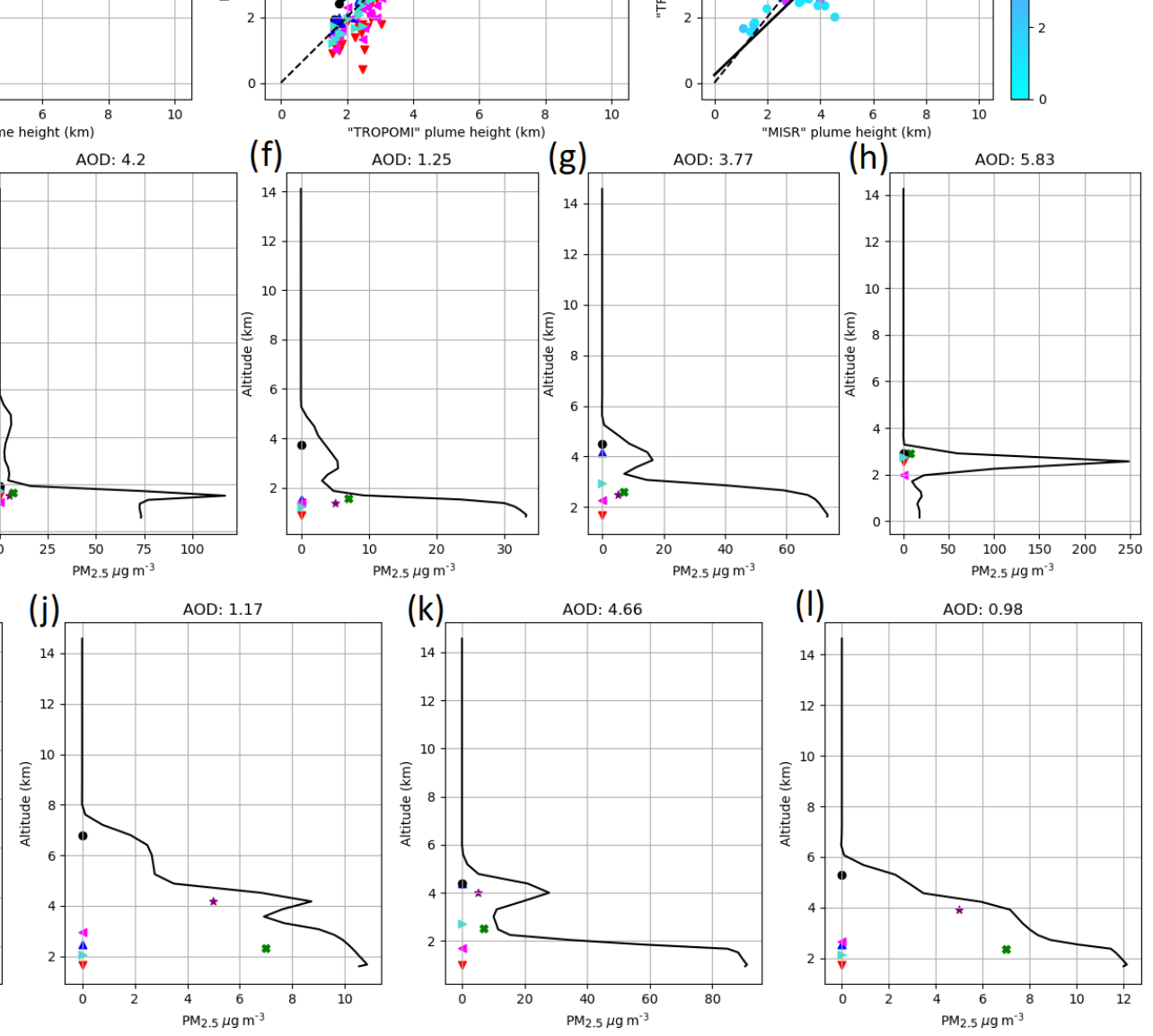

Figure 1. Observing system simulation experiments (OSSE) results for the simple methods (see text) versus (a) simulated MISR and (b) simulated TROPOMI heights. Simulated MISR versus TROPOMI plume heights are shown in (c), together with the statistics of the line of best fit (correlation coefficient $R$, slope $s$, and mean difference \pm standard deviation in kilometres). Five example profiles in which simulated MISR and TROPOMI plume heights agree well are shown in (d)-(h), and four example profile where there are significant differences are shown in (i)-(l). The TROPOMI-OSSE and MISR-OSSE heights (d-l) are plotted with a $\mathrm{PM}_{2.5}$ offset simply for visualization.

true aerosol size distribution of a fire smoke plume. However, the approximation can be used since the retrieved layer contributing the most to the reflective contrast does not depend on the exact size distribution used. We have also estimated the plume height assuming organic carbon (OC) with a refractive index of $1.36+0.001 i$ (at $\mathrm{RH}=99 \%$ ) and found negligible differences between the plume heights obtained assuming $\mathrm{BC}$ and $\mathrm{OC}$ refractive indices for most cases (see Figs. S1 and S2 in the Supplement). The surface albedo provided in the TROPOMI layer height product is used for each different scene (for MISR and TROPOMI), and five orders of scattering were computed. For the MISR and the TROPOMI OSSE (MISR-OSSE and TROPOMI-OSSE; see below), it is critical to have fine layering in the radiative transfer model simulations that serve as the pseudo-observations in order to properly capture the shape of GEM-MACH aerosol profile. For MISR simulations using VECTOR, $100 \mathrm{~m}$ layering was used in the lowest $20 \mathrm{~km}$ of the atmosphere, and, thus, the GEM-MACH aerosol profiles were interpolated to $100 \mathrm{~m}$ layers. 


\subsection{TROPOMI-OSSE plume heights}

To simulate the layer height retrieval from TROPOMI, we used MODTRAN 5.2 (Berk, 2013, and references therein) to take advantage of the correlated- $k$ option for simulating radiances in an absorption band, namely the oxygen $A$ band $(\sim 762 \mathrm{~nm})$. The correlated- $k$ absorption parameter data are specified at $1 \mathrm{~cm}^{-1}(\sim 0.06 \mathrm{~nm}$ at $760 \mathrm{~nm})$ resolution. The terrain height for the MODTRAN modelling is obtained from GEM-MACH for each scene. The radiance is convolved with a triangular slit function with a full width at half maximum of $0.5 \mathrm{~nm}$ to account for the TROPOMI spectral resolution in channel 6 (Veefkind et al., 2012), which covers the $\mathrm{O}_{2} A$ band. The discrete ordinates method is used to simulate the radiative transfer with eight streams. The solar zenith angle and viewing nadir angle of each scene are taken into account (as was done for MISR-OSSE). MODTRAN expects an aerosol extinction profile as an input rather than an aerosol number density profile. This conversion involves scaling the number density profile determined in Sect. 3.1 such that the aerosol optical depth simulated by MODTRAN is equal to the aerosol optical depth simulated for MISR. The A-band absorption depth is used as the observable in the retrieval and is computed using the following ratio: $\left(I_{762.95}+I_{760.75}\right) /\left(I_{768.94}+I_{768.82}+I_{759.01}\right)$, where the subscripted numbers are the wavelength (in nanometres) at which spectral radiances are simulated. The numerator is the sum of the radiance at two wavelengths for which $\mathrm{O}_{2}$ is strongly absorbing, and the denominator contains three wavelengths in the continuum (i.e. minimal absorption). The retrieval method is iterative and seeks to match the observed absorption depth with the forward modelled one by solely varying the layer height during the retrieval. The observations involve using the GEM-MACH aerosol profile, whereas for the forward model simulations during the retrieval, the profile shape is not known, and we assume that the aerosol layer has a vertical extent of $500 \mathrm{~m}$ with no aerosol outside this $500 \mathrm{~m}$ layer. Note that TROPOMI operational algorithm uses spectral fitting to retrieve AER_LH, whereas a simple ratio has been used here, similar to Xu et al. $(2017,2019)$. The reported layer height is the middle of this layer.

\subsection{Plume height evaluation using pseudo-observations}

In this section, the modelled plume heights, derived using five simple methods, and the simulated plume height, using modelled profiles with the MISR (Sect. 3.1) and TROPOMI (Sect. 3.2) retrieval methods, are compared. In Sect. 3.1 and 3.2, we described methods based on remote sensing for plume height estimation using modelled aerosol profiles. These simulations are, however, time consuming and therefore not practical for the model-satellite comparison as thousands of aerosol profiles would have to be simulated. Instead, several simpler methods are considered to define plume heights from model output, which can be used to compare the modelled output to satellite observations in the subsequent section. These methods define plume height as (1) the altitude of the model layer of the maximum $\mathrm{PM}_{2.5}$ concentration (shown as down-pointing red triangles in Fig. 1); (2) the altitude of the highest model layer that exceeds $\mathrm{PM}_{2.5}$ concentration of $10 \mathrm{\mu g} \mathrm{m}^{-3}$ (shown as blue down-pointing triangles in Fig. 1); (3) the altitude of the highest model layer that exceeds $10 \%$ of the maximum $\mathrm{PM}_{2.5}$ concentration (this definition has previously been used in Raffuse et al. (2012); shown as black dots in Fig. 1); (4) the average height between methods (1) and (2) (shown as right-pointing cyan triangles in Fig. 1); and (5) a $\mathrm{PM}_{2.5}$ concentration weighted average of model layer heights (shown as left-pointing magenta triangles in Fig. 1). The results of this simulated plume height comparison are shown in Fig. 1 with the reference $1: 1$ line shown as a black dash. These results show that the methodology in which the top layer of the plume is that exceeds $10 \mu \mathrm{g} \mathrm{m}^{-3}$, method (2), is closest to the MISR simulated plume heights (Fig. 1a) with a mean difference ( \pm standard error) of $-98 \mathrm{~m}( \pm 181 \mathrm{~m})$. Method (3) overestimates the plume height consistently for all plumes. Methods (1), (2), (4), and (5) are very close for many aerosol profiles, but for profiles containing multiple plumes, methods (2), (4), and (5) underestimate the MISR-simulated plume height. For the TROPOMI-OSSE (Fig. 1b), simulated plume heights with method (4) are the closest with a mean difference of $37 \pm 90 \mathrm{~m}$, and except two profiles, the differences are all less than $200 \mathrm{~m}$. For simple plumes with one strong aerosol peak (Fig. 1d-h), method (2) is close to the simulated TROPOMIOSSE plume height but tends to overestimate the plume height of more complicated plumes with multiple aerosol layers, while methods (1) and (5) tend to underestimate the TROPOMI-OSSE plume height. Using method (3), with plume height as the altitude of the highest model layer that exceeds $10 \%$ of the maximum $\mathrm{PM}_{2.5}$ concentration, overestimates the plume height for all plumes. Lastly, the simulated plume heights using the MISR and the TROPOMI approaches are compared over different AOD simulated using the VECTOR RT model (Fig. 1c). Overall, the plume heights estimated using the five different simple methods are consistent with the satellite retrievals for most plumes; however, there are cases in which the TROPOMI-OSSE plume heights are lower in comparison to the MISR-OSSE plume heights. We have found these to be unrelated to the AOD of the plume. The average mean difference ( \pm standard deviation) between the simulated aerosol layer heights between MISR and TROPOMI is $0.52 \pm 0.84 \mathrm{~km}$. This difference can be attributed purely to the different observation/retrieval methods of the aerosol layer height between the two instruments.

The differences between the MISR-OSSE and TROPOMIOSSE plume heights were further investigated, and Fig. 1d1 show examples of the profiles used, along with the retrieved plume heights. Profiles for which the MISR-OSSE and TROPOMI-OSSE plume heights agree well are displayed in Fig. 1d-h, and all show one single dominant plume. 
Profiles that result in differences between MISR-OSSE and TROPOMI-OSSE are more complicated profiles consisting of multiple aerosol layers (Fig. 1i-1). In these cases, MISR observes the altitude of the upper plume, whereas the $A$-band method used for TROPOMI (and EPIC) retrieves an optical centroid altitude (Xu et al., 2019). Note that retrieving a single layer height can be difficult particularly when the volume enclosing the plume takes the shape of a column or when there are multiple plumes at different altitudes due to either multiple source locations (i.e. points of origin) or shifts in the wind direction or atmospheric stability during the course of emissions. Large differences between TROPOMI and MISR might be an indicator that multiple plumes are present.

\section{TROPOMI aerosol layer heights}

As discussed in the previous section, there are fundamental differences between the plume heights observed by the different satellites. Here, the differences and correlation between the satellite plume height observations are discussed in terms of what is expected from the OSSE results and due to different observation times.

\subsection{Comparison to MISR}

In total, we found 115 fire plumes for which the MISR layer height retrieval was of good (87) to fair (29) quality and which were captured by both MISR and TROPOMI between June and August 2018 in North America. Most of the plumes were located in western Canada and the western US where fire activity was high to extreme for the year. There were few plumes in eastern Canada, in the provinces of Ontario and Quebec, or in the states of Wyoming and Colorado in the central US. Due to the differences in sensor spatial resolution, each plume spanned many pixels, on the order of a several hundred for MISR and a dozen for TROPOMI. For the comparison, we investigated the maximum plume heights and the mean plume heights within those fire plumes. An example is shown in Fig. 2 for two fires (the fire hotspot is shown as red dots) in central British Columbia on 6 August 2018 at approximately $53^{\circ} \mathrm{N}, 126^{\circ} \mathrm{W}$. The plume height pixels from MISR, TROPOMI and GEM-MACH are overlaid on the VIIRS true colour visible imagery showing the smoke plume (obtained from NASA Worldview; https://worldview. earthdata.nasa.gov/, last access: 25 March 2020). For MISR a plume has to be digitally outlined in MINX (dashed red line in Fig. 2), this plume polygon was also used to define the spatial extent of the same smoke plume for TROPOMI. As MISR overpasses a location approximately $2 \mathrm{~h}$ earlier than TROPOMI, MISR, and TROPOMI do not observe the fires at exactly the same time. Forest fire emissions typically follow a diurnal cycle with a decrease in emissions and intensity during the night and increase throughout the day until the late afternoon; hence the plume might be expected to grow between the two overpass times. To account for plume growth from atmospheric dispersion over this time, the plume shape derived for the MISR analysis was increased spatially in size by $0.15^{\circ}$ in longitude and latitude for TROPOMI (see dashed navy line in Fig. 2). All pixels within this slightly enlarged plume outline were assumed to belong to the same fire plume, and the mean and the maximum of those observations were calculated for comparison with MISR. The enlarged polygon is used as a guidance on which pixels from TROPOMI belong to the same plume that is outlined in MINX; there is no manual input or outlining required for the TROPOMI algorithm. If the enlarged polygon is too large or the plume does not cover the whole area, the mean will not be affected as the TROPOMI plume heights are set to a fill value (and masked) if no plume has been detected or retrieval did not pass the quality control. Since the resolution of the MISR pixels is around $1 \mathrm{~km} \times 1 \mathrm{~km}$ and of much finer resolution than that of TROPOMI $(5 \mathrm{~km} \times 7 \mathrm{~km})$, greater variability and extremes in plume heights are expected from MISR, with significantly higher sampling of pixel within the same plume, as spatial smoothing of layer height is limited. To correct the impact of sensor resolution on the maximum plume height derived from a cluster of pixels in a given plume, the MISR pixels were averaged and binned on a $0.05^{\circ} \times 0.05^{\circ}$ grid to approximately match the TROPOMI resolution.

The results of the comparison between the TROPOMIand MISR-derived plume heights for 155 identified collocated fire plumes from both sensors in North America are shown in Fig. 3. The average maximum plume heights above ground level for the 2018 fires in North America are, on average, $2 \mathrm{~km}$ (ranging between 0.4 and $5.5 \mathrm{~km}$ ) and $1.6 \mathrm{~km}$ (ranging between 0.01 and $8.4 \mathrm{~km}$ ) for MISR and TROPOMI, respectively. The mean plume heights (above ground level) from the 155 fire plumes are on average $1.4 \mathrm{~km}$ (ranging between 0.3 and $3.2 \mathrm{~km}$ for MISR) and $0.8 \mathrm{~km}$ (ranging between 0.01 and $2.8 \mathrm{~km}$ for TROPOMI). Overall, TROPOMI's maximum and mean plume height is on average $0.59 \pm 1.3 \mathrm{~km}$ and is $0.55 \pm 0.74 \mathrm{~km}$ lower than the plume height derived from MISR, respectively, when horizontal resolution impacts have been removed by averaging, as noted above. The mean difference found for the TROPOMI and MISR observed plume heights is similar to those found for the simulated plume heights of the OSSE. The maximum plume heights from all smoke plumes are similar; however, they have a large spread $(\sigma=1.3 \mathrm{~km})$ and only a moderate correlation $(R=0.44)$, even when taking the difference in resolution into account by binning the data. This is expected, and in fact the results are reasonable, since the maximum plume height will only contain the observations of a single TROPOMI pixel and there is a time difference between 0.5 and $3 \mathrm{~h}$ between the TROPOMI and MISR overpass in which plume heights can change significantly. The average plume heights, a more aggregated quantity, have a better correlation with a correlation coefficient, $R$, with $R=0.61$, and slope of best fit, $s$, with $s=0.8$, and TROPOMI bi- 

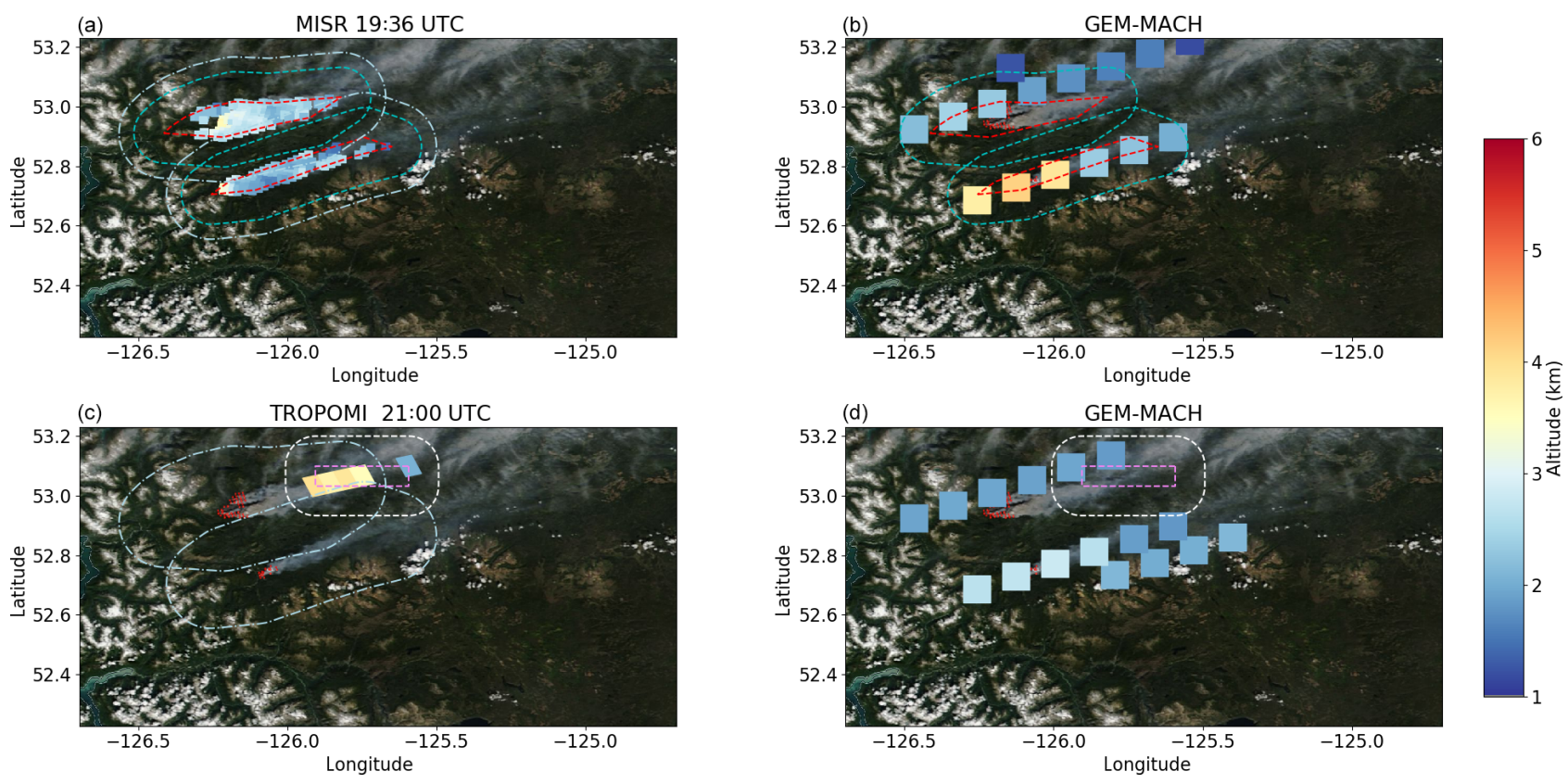

Figure 2. Example of two fire plumes on 6 August 2018 in British Columbia, Canada (approximately $56^{\circ} \mathrm{N}, 126^{\circ} \mathrm{W}$ ). The colour scheme illustrates the altitude of the plume (a) as observed by MISR at 19:38 UTC, (b) modelled in GEM-MACH using CFFEPS at 19:38 UTC, (c) observed by TROPOMI at 21:00 UTC, and (d) modelled by GEM-MACH using CFFEPS at 21:00 UTC. The dashed lines outline the shape of the plume used for the comparison (see text for further details). (Underlying VIIRS images obtained from NASA Worldview (https://worldview.earthdata.nasa.gov/, last access: 25 March 2020).

ased low. This low bias of the TROPOMI observations of plume heights is expected based on the retrieval technique (see Sect. 3), where MISR observes the top plume height and TROPOMI observes an average plume height when multiple layers of aerosols are present. Furthermore, despite the spatial adjustment of expanding the sampling footprint of the MISR plume, the $0.5-3 \mathrm{~h}$ earlier overpass time of MISR is likely sampling plume heights earlier in the day when the planetary boundary layer (PBL) is not fully established and of lower fire intensity. TROPOMI plume height observations are, therefore, expected to be slightly higher compared to MISR because of general increases in fire intensity in the afternoon enhancing plume advection. However, the differences between the satellite observations and the differences of the OSSE simulated plume heights based on the satellite retrieval algorithm (Sect. 3) are similar; no increasing plume height is apparent from this TROPOMI and MISR dataset.

The regional distribution of the different plume heights are illustrated in a map over locations of fire hotspots during the analysis period (see Fig. 3d). Table 1 summarizes the different plume heights found by MISR in comparison to TROPOMI. The average plume heights for the maximum and mean plume height within each of the 115 plumes are shown for fires in different types of biomes as classified by the International Geosphere-Biosphere Programme (IGBP). For the comparison with MISR, enough observations within our dataset were only found for evergreen fires. To be able to do a quantitative regional comparison for additional vegetation types, more smoke plume observations are required.

\subsection{Comparison to CALIOP}

For the comparison between CALIOP and TROPOMI, only CALIOP plume heights over North America are retained; filtered out (with Feature_Classification_Flags) were the ones categorized as clean marine, dust, polluted continental and clean continental plumes. Thus, only plume heights containing smoke or polluted dust were selected (we found that fire plume aerosols are classed as either smoke or polluted dust). The maximum and mean of the TROPOMI aerosol layer height within $\pm 0.15^{\circ}(\sim 15 \mathrm{~km})$ of the CALIOP observations were compared. Similar to Gonzalez-Alonso et al. (2019) we use the top and plume base from the CALIOP L2 product (aerosol layer product $\mathrm{v} 4$ ), which are on a horizontal resolution of $5 \mathrm{~km}$, similar to that of TROPOMI, and thus no additional corrections to the sampling footprint were carried out. Note that the CALIOP data are averaged to $5 \mathrm{~km}$, however along a narrow swath $(\sim 100 \mathrm{~m})$, differences could arise due to the different sampling. On average there is a small overpass difference between these two sensors varying between -1 and $2 \mathrm{~h}$ (CALIOP-TROPOMI overpass) for this dataset, so the forest fire plume height comparisons may also be affected by plume evolution between overpasses. Unlike TROPOMI, which provides one plume height at each sampling pixel, the active lidar on CALIOP provides a detailed 
(a)

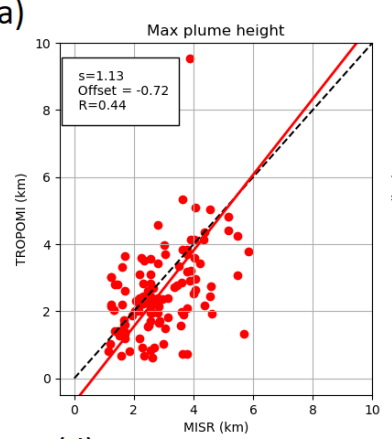

(b)

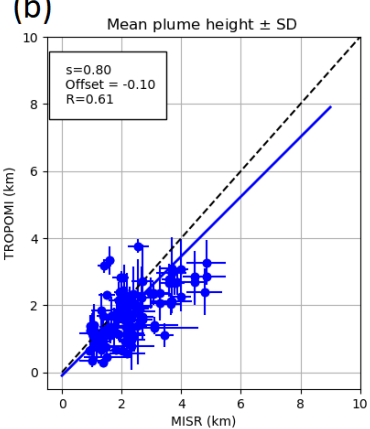

(c)

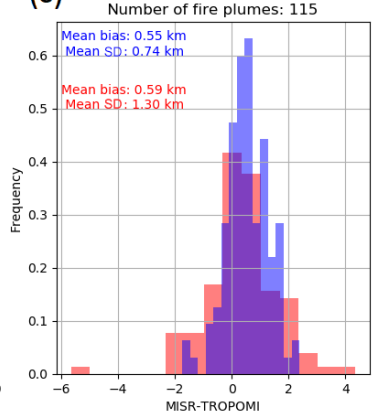

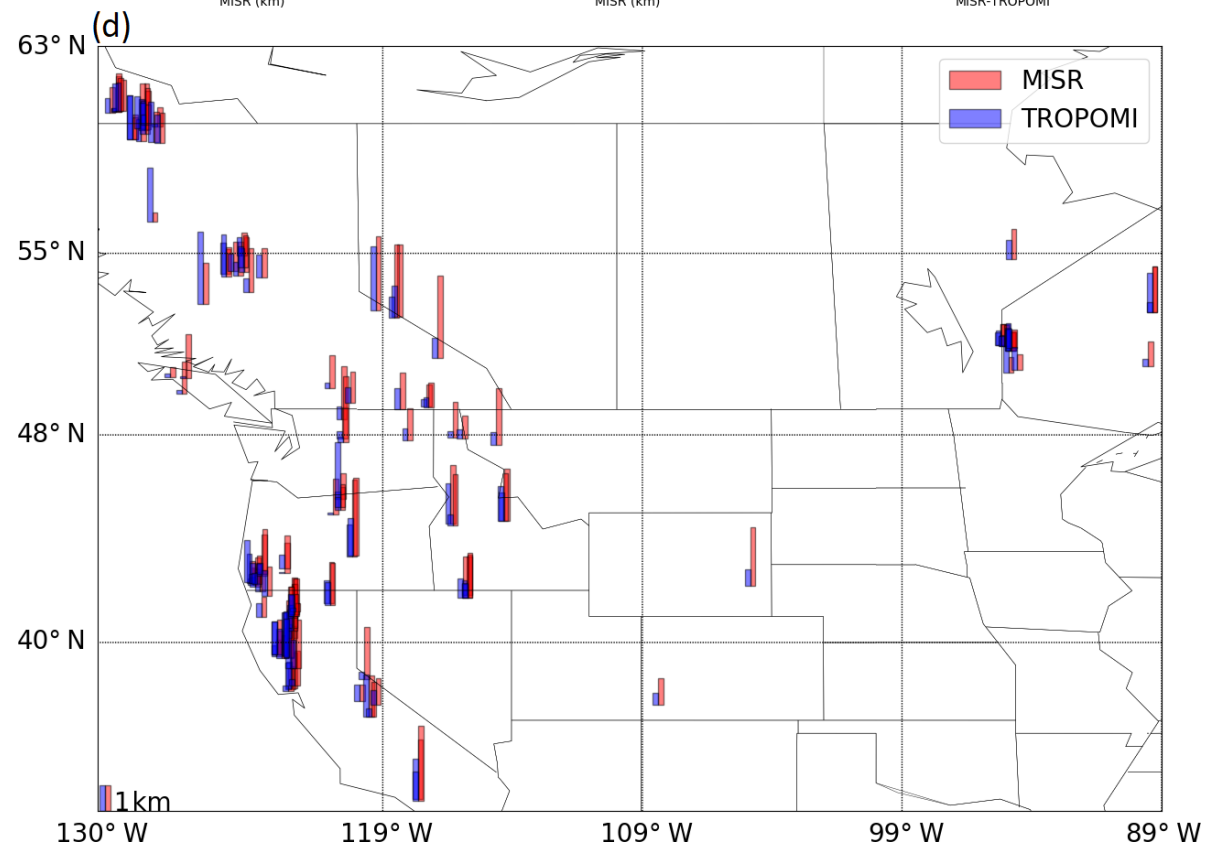

Figure 3. TROPOMI-MISR plume height comparison. In total 115 fire plumes were compared (all between June and August 2018) in terms of (a) maximum plume height and (b) mean plume height within one wildfire plume, together with the statistics of the line of best fit (correlation coefficient, $R$, and slope, $s$ ). Panel (c) shows the histogram for the differences in plume height (MISR - TROPOMI) for the maximum (blue) and mean (red) plume height. (d) A map showing the regional distribution of those fires with the mean plume height (above ground level) for TROPOMI (blue; left bar) and MISR (red; right bar).

plume profile, some with multiple layers of aerosol in a profile. Here, we define the thickness of the plume as the difference between plume top and plume base; CALIOP's midlayer height (average between plume top and base) are compared to TROPOMI's aerosol mid-layer heights. We further found that very high plumes $(>8 \mathrm{~km})$ observed by CALIOP were not captured by TROPOMI, likely because they are optically quite thin, and those have been removed from the comparison. Sometimes multiple layers of aerosols can occur in a CALIOP profile. We investigated additional CALIOP plume height interpretations to find the most representative layer height for the comparison to TROPOMI. They are (1) the CALIOP top layer height, (2) the average of all CALIOP-identified aerosol layers and (3) the thickest (geometrical thickness) CALIOP aerosol layer. Overall, we found that the first of these definitions is not appropriate for the
TROPOMI comparison as the top aerosol layer in CALIOP can be a very thin plume in the upper troposphere/lower stratosphere that is not captured by TROPOMI. The second methodology comparing the CALIOP average of all aerosol plumes to TROPOMI was sometimes also biased by very low concentration layers of CALIOP aerosol at high elevations. The third methodology was not affected by the issues for the other two methods; using comparing the CALIOP geometrically thickest aerosol layer with the TROPOMI aerosol layer height seems the most applicable for the plume height comparison between those two different satellite instruments.

Figure 4 summarizes the CALIOP-TROPOMI plume height comparison for (a) geometrically thick plumes $(>1.5 \mathrm{~km})$, (b) geometrically thin plumes, (c) a histogram of the differences, (d) how the statistics of the comparison change for different plume thickness filters and (e) how 
Table 1. Summary of plume heights observed in different regions; shown is the mean (standard deviation) of the maximum and mean plume heights for all plumes for different types of wildfires (IGBP biome). The reported altitudes are all in kilometres above ground level.

\begin{tabular}{lrrr|rr}
\hline \multirow{2}{*}{ Biome name (class) } & No. plumes & \multicolumn{2}{c|}{ Maximum $(\mathrm{km})$} & \multicolumn{2}{c}{ Mean $(\mathrm{km})$} \\
\cline { 3 - 6 } & & MISR & TROP & MISR & TROP \\
\hline All & 115 & $2.0(0.09)$ & $1.4(0.05)$ & $1.4(0.06)$ & $0.7(0.11)$ \\
Evergreen (1) & 84 & $1.8(0.09)$ & $1.4(0.05)$ & $1.3(0.06)$ & $0.8(0.09)$ \\
\hline & & MISR & CFFEPS & MISR & CFFEPS \\
\hline All & 70 & $1.7(0.9)$ & $2.0(1.0)$ & $1.3(0.6)$ & $1.3(0.4)$ \\
Evergreen (1) & 25 & $1.6(1.0)$ & $1.6(0.6)$ & $1.2(0.6)$ & $1.1(0.4)$ \\
\hline & & TROP & CFFEPS & TROP & CFFEPS \\
\hline All & 671 & $2.2(1.6)$ & $2.5(1.2)$ & $0.7(0.5)$ & $1.1(0.6)$ \\
Evergreen (1) & 263 & $2.1(1.3)$ & $2.3(0.9)$ & $0.7(0.4)$ & $1.1(0.6)$ \\
Woody savannas (8) & 197 & $2.3(1.8)$ & $2.3(1.0)$ & $0.7(0.4)$ & $1.1(0.6)$ \\
Grassland (10) & 136 & $2.2(1.7)$ & $3.0(1.8)$ & $0.7(0.5)$ & $1.5(0.9)$ \\
\hline
\end{tabular}

the statistics of the comparison change for different surface albedo. The results show that the difference between the plume height observed by TROPOMI and CALIOP depends significantly on the thickness of the plume (as derived from CALIOP). Thicker plumes seem to be better captured by TROPOMI, and the thicker the plume the smaller the difference between the CALIOP and TROPOMI plume height. TROPOMI was biased low, on average by $2.1 \mathrm{~km}$, in comparison to CALIOP for thin smoke plumes (thickness of less than $1.5 \mathrm{~km}$ ). Much better agreement and an improved correlation between the two satellite datasets are found for thicker plumes (see Fig. 4d). The mean difference reduces with the thickness of the plumes; the mean difference between the TROPOMI and CALIOP mid-aerosol layer is just $50 \mathrm{~m}$ for very thick plumes $(>3 \mathrm{~km})$. The geometrically thick plumes are typically optically thicker plumes, too. The reason for the reduced bias with increasing layer thickness is probably the sensitivity of the TROPOMI AER_LH algorithm to the scattering layer in the scene, which is more and more dominated by the surface if the aerosol layer is optically thinner. The correlation plot and histogram are shown in Fig. 4 for thin plumes (shown in blue) and thick plumes ( $>1.5 \mathrm{~km}$; shown in red). The distribution of the differences between the TROPOMI and CALIOP plume height is a normal distribution, with a smaller spread for thick plumes. From this analysis it also appears that lower plumes, below approximately 4-4.5 km, are better captured by TROPOMI (see Fig. 4). Figure $4 \mathrm{e}$ shows that the differences between CALIOP and TROPOMI increase with increasing surface albedo, consistent with the idea that the TROPOMI retrieval algorithm is more sensitive over dark surfaces and possesses smaller uncertainties (Sanders and de Haan, 2016; Xu et al., 2019).

\section{Model plume height evaluation}

The modelled plume heights are compared to satellite observations with the aim to evaluate the modelled plume injection heights and to determine the strengths or weaknesses of the model. In order to compare the FireWork-modelled plume heights to the satellite observations, the hourly output of the model is interpolated to the time of the satellite overpass. The mean and maximum plume heights within individual fire plumes were compared. As mentioned in Sect. 2.4, MISR and TROPOMI detects smoke plume height differently; thus, the modelled plume heights extracted for comparison are also different. For the comparison with the MISR plume heights, the model plume height is defined as the highest model layer containing a $\mathrm{PM}_{2.5}$ concentration greater than $10 \mu \mathrm{g} \mathrm{m}^{-3}$. For the comparison to TROPOMI, the model plume height was defined as the average height between the altitude of the maximum $\mathrm{PM}_{2.5}$ concentration within the grid column and the highest layer containing a $\mathrm{PM}_{2.5}$ concentration exceeding $10 \mu \mathrm{g} \mathrm{m}{ }^{-3}$.

\subsection{Comparison with MISR}

Similar to what was done for the TROPOMI-MISR comparison, the area of the plume is defined by the expanded MISR plume outline (by $0.1^{\circ}$ ), and all points within this enlarged polygon (an example can be seen in Fig. 2 - the enlarged polygon used for the model comparison is shown as a dashed blue line) are considered as part of the plume. Given that FireWork is a forecast product, this expanded polygon is used for the comparison to compensate for errors in wind forecast speeds and direction within the model and for uncertainties related to temporal interpolation between hourly output and satellite overpass. Furthermore, given the coarse model resolution compared to MISR pixel, the expanded plume footprint allows for more points to be extracted for comparison. 

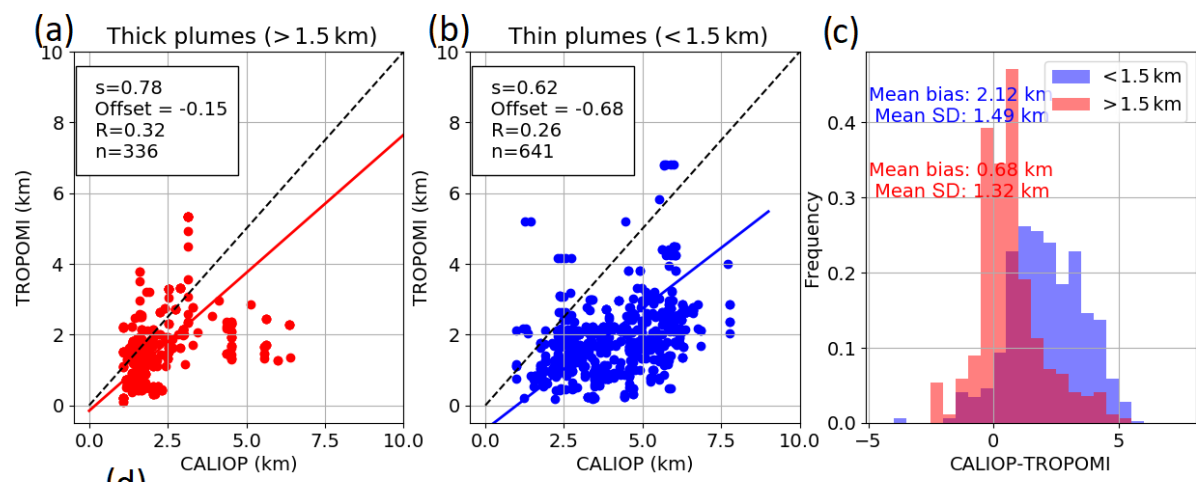

(d)

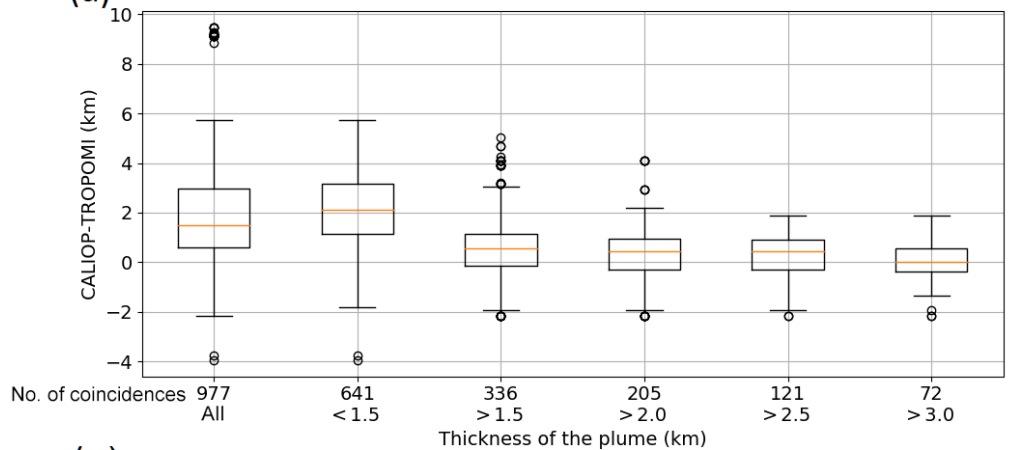

(e)

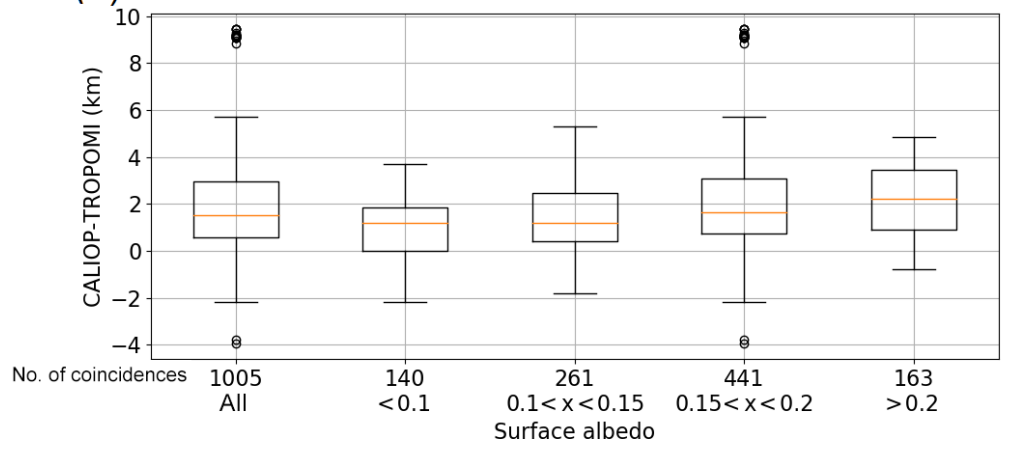

Figure 4. CALIOP-TROPOMI comparison for (a) geometrically thick plumes $(>1.5 \mathrm{~km})$ and (b) geometrically thin plumes $(<1.5 \mathrm{~km})$, together with the statistics of the line of best fit (correlation coefficient, $R$, slope, $s$, and number of observations, $n$ ). The plume thickness is determined by the CALIOP top and base plume height. Panel (c) shows the histogram for the differences in plume height (CALIOP - TROPOMI) for thick (red) and thin (blue) plumes. Panel (d) shows the statistics for different plume thickness filters and (e) for different ranges of surface albedo.

All points with elevated $\mathrm{PM}_{2.5}$ within this extended polygon are considered part of the same plume. Again, to account for the difference in resolution when comparing the maximum plume height, MISR pixels have been binned to $0.1^{\circ} \times 0.1^{\circ}$, to the approximate resolution of the model.

We found that the modelled plume heights are very similar but on average slightly higher than the ones observed by MISR. Overall, the modelled plume heights represent the observations very well in terms of mean and maximum plume heights, with differences of $-0.06 \pm 0.68$ and $-0.32 \pm 1.21 \mathrm{~km}$, respectively. Figure $5 \mathrm{a}-\mathrm{c}$ summarize the results for the comparison between MISR and CFFEPSv4.0. In total 70 fire plumes were compared (all between June and
August 2018) in terms of (a) maximum plume height and (b) mean plume height. A map illustrating the regional distribution of the mean plume heights is shown in Fig. 5d.

The FireWork modelled plume heights with forecast meteorology are on average less than $100 \mathrm{~m}$ higher compared to the MISR observations. The modelled plume heights correlate well with the satellite observations with $R=0.73$ for the mean plume heights. The maximum plume height within one plume is also well represented with a correlation coefficient of $R=0.53$; the model overestimates the maximum plume height on average by $+0.32 \mathrm{~km}$. These are very encouraging results for modelled versus satellite-observed plume heights, especially, considering the assumptions that were parameter- 

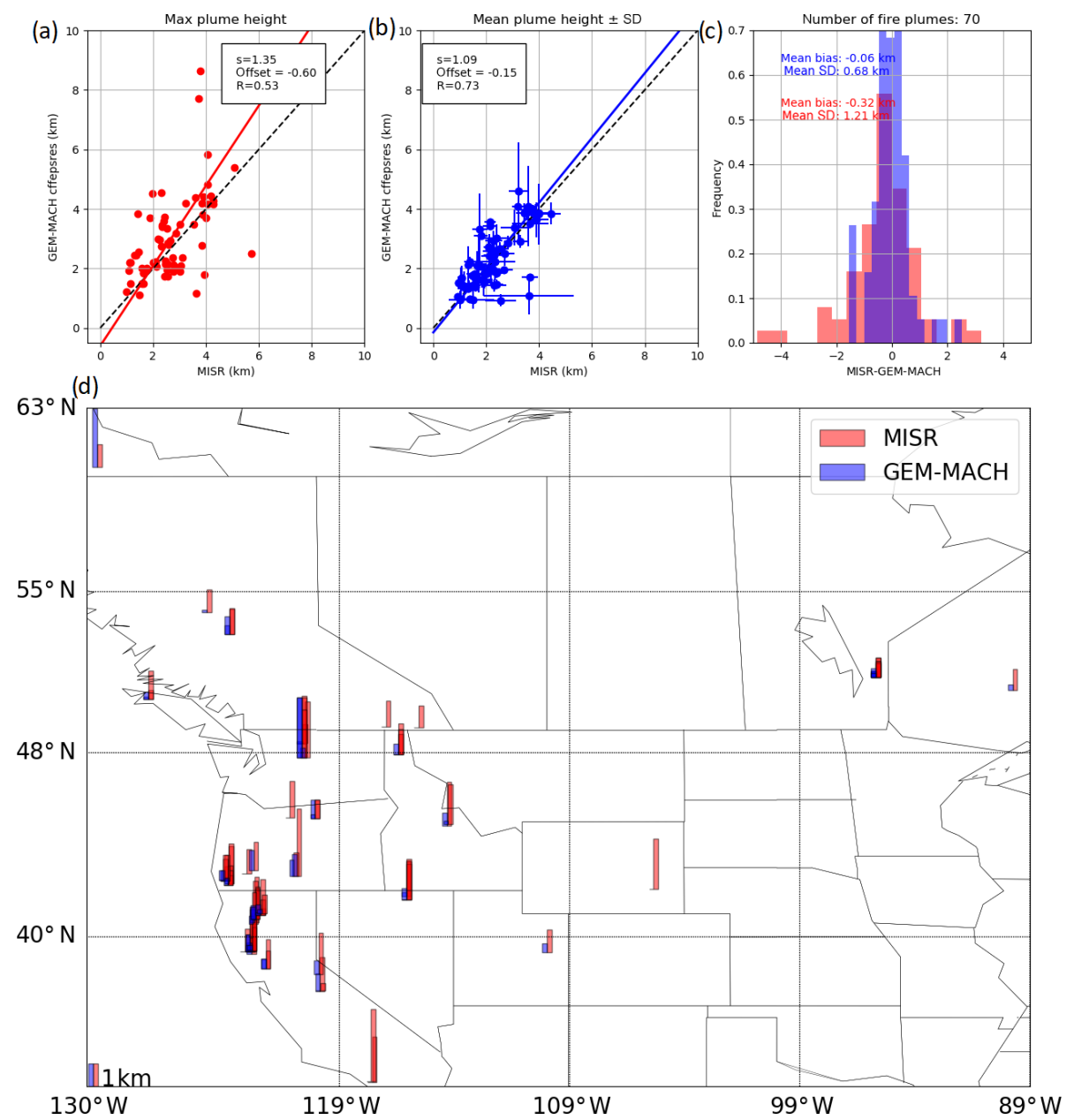

Figure 5. Modelled plume height versus MISR-derived plume height (a-c). In total 70 fire plumes were compared (all between June and August 2018) in terms of (a) maximum plume height and (b) mean plume height within one wildfire plume, together with the statistics of the line of best fit (correlation coefficient, $R$, and slope, $s$ ). Panel (c) shows the histogram for the differences in plume height (MISR - model) for the maximum (blue) and mean (red) plume height. Panel (d) shows the regional distribution of plume heights above ground level for MISR (red, left bar) and CFFEPS (blue, right bar).

ized in the modelling fire plume height, such as amount of fuel consumed, area burned, energy released, modelled atmospheric profiles and dispersion. There were not only small mean differences small but also a good correlation between the observations and the model for both mean and maximum plume heights. The error difference for the plume plumes analysed here have a normal distribution (see Fig. 5c). Significant of progress has been made in recent years in terms of modelling plume rise for biomass burning. For example, Raffuse et al. (2012) found that on average the modelled plume heights agreed with the observations, but correlations between observed and simulated plume heights was poor. However, modelled plume heights in Raffuse et al. (2012) were calculated using a Briggs plume rise approach as opposed to calculating the energy balance in multiple atmospheric layers. The latter approach, used in CFFEPS, was found to result in more accurate predictions of surface daily maximum $\mathrm{PM}_{2.5}, \mathrm{NO}_{2}$, and $\mathrm{O}_{3}$ than the use of Briggs formula (Chen et al., 2019). At least part of the improved model predictive performance of the ECCC FireWork forecast may be attributable to these radiative transfer calculations within CFFEPS, with the version used here (v4.0) also including a higher vertical resolution than the v2.03 version described in Chen et al. (2019). The differences between MISR- and FireWork-modelled plume heights for different biomes are summarized in Table 1 showing that for evergreen forest fires the modelled and MISR observations agree well on average. There were not enough fire plumes available from the FireWork-MISR comparison to compare other biomes. The number of fire plumes that have been compared to the FireWork is slightly lower than for the TROPOMI-MISR comparison; some smaller fires can be missed by the model or the modelled aerosol concentration does not reach $10 \mu \mathrm{g} \mathrm{m}^{-3}$. 

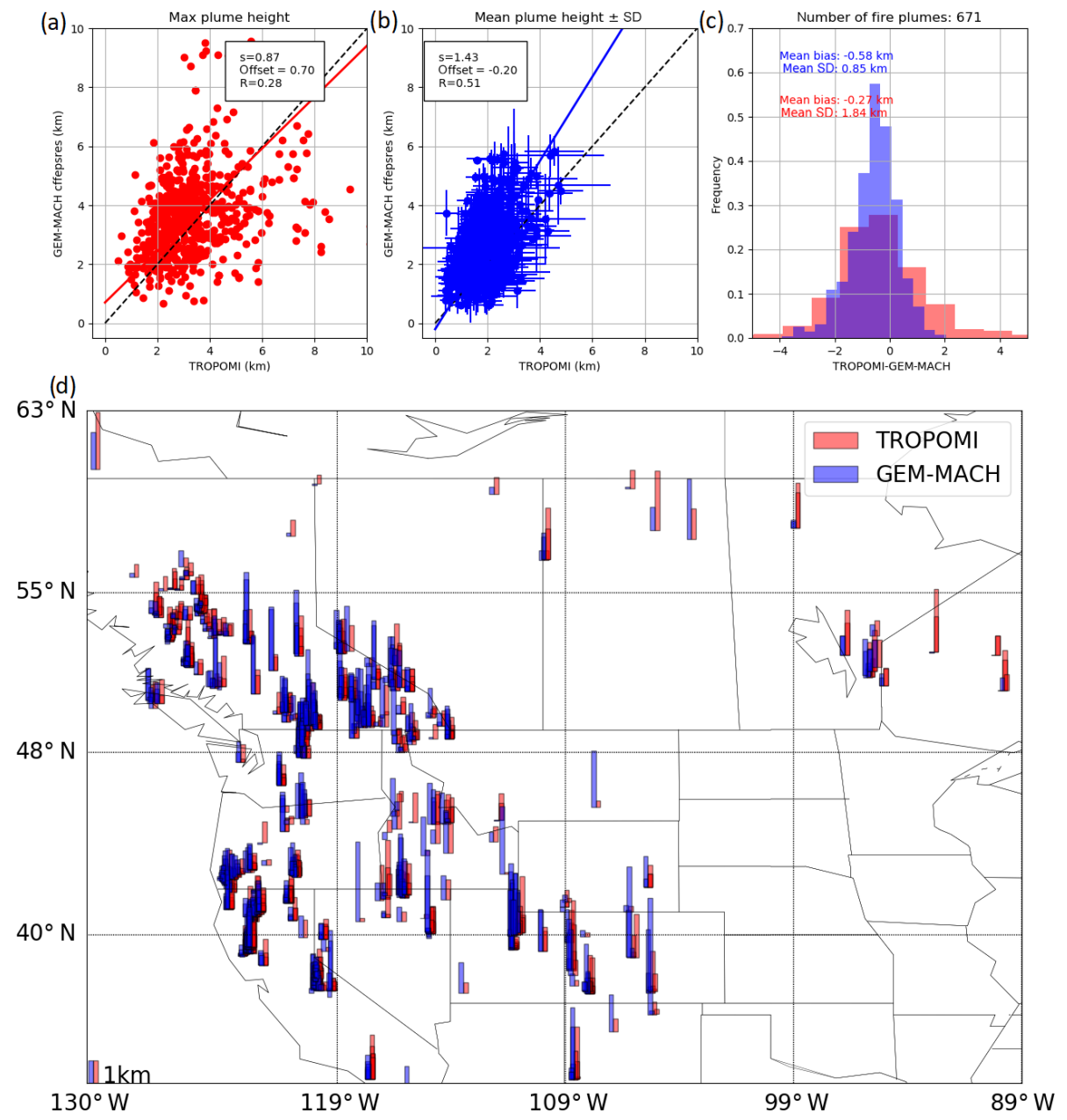

Figure 6. Same as Fig. 5 but for the TROPOMI-model comparison.

\subsection{Comparison with TROPOMI}

For the comparison of FireWork modelled plume height to TROPOMI, the spatial extent of the plume is defined as the polygon surrounding TROPOMI's minimum and maximum latitude and longitude (shown as a dashed purple line in Fig. 2) in which a predefined smoke or aerosol layer was present near a fire hotspot as identified by MODIS Aqua. Similar to the process with the MISR comparison, this polygon is then increased by $0.1^{\circ}$ (dashed black line in Fig. 2) to account for the errors in forecast wind direction and speed within the model. As the resolution of TROPOMI is higher than the resolution of the GEM-MACH model, for the maximum plume height comparison the TROPOMI observations are binned to $0.1^{\circ} \times 0.1^{\circ}$, approximately the resolution of the model, and the TROPOMI gridded data are paired with model output sampled at the TROPOMI overpass time. Overall for North America June-August 2018, 671 coincident fire plumes were found for the model comparison. This number is significantly higher than for the comparison between FireWork and MISR, because of the better geospatial coverage of TROPOMI compared to MISR, and, thus, less fires are missed by TROPOMI. The results for the TROPOMI and model comparison are shown in Fig. 6, and the results summarizing the averages for different biomes are in Table 1.

Moderate correlation was found for the TROPOMI-model comparison ( $R$ in the 0.3 to 0.5 range; see Fig. 6 ). The model plume height is on average higher than the TROPOMI observations. The average differences (TROPOMI-model) in the maximum and mean plume height are of $-0.27 \pm 1.84$ and $-0.58 \pm 0.85 \mathrm{~km}$, respectively.

For the plume heights for different biomes, also with the increased number of fire plumes with TROPOMI, only minor differences are observed between the different biomes. Overall, it seems that CFFEPS struggles the most with grassland fires where the average plume height is about $0.8 \mathrm{~km}$ higher than the TROPOMI observations. Plume heights from evergreens and woody savannas seem to agree well with the observations. Looking at the TROPOMI plume height, fire plumes from all of the here-presented biomes have on average a maximum plume height between 2.1 and $2.3 \mathrm{~km}$ and an average mean plume height of $0.7 \mathrm{~km}$. 


\section{Summary and Conclusions}

We compared wildfire plume heights from TROPOMI- and MISR-derived plume heights and CALIOP aerosol profiles for the 2018 fire season in North America (June to August). The only satellites that could globally observe plume heights before the launch of TROPOMI were MISR and CALIOP. MISR and CALIOP are unique in their ability to vertically resolve the atmospheric aerosols globally; however, those two satellites have a narrow swath, with a global coverage every week and $16 \mathrm{~d}$, respectively. This means that many fire plumes are missed by these satellites. The plume height product from TROPOMI is a potential game changer in terms of frequency and availability of observations; aerosol plume heights from TROPOMI have the advantage of daily global coverage, and a NRTI version exists that is available approximately $3 \mathrm{~h}$ after the overpass. CALIOP aerosol profiles are available with an approximately 1-day delay, but MISR-derived plume heights on the other hand require time-consuming manual input and are not available NRTI. As such, TROPOMI aerosol layer heights can provide value to the modelling communities by improving air quality forecasting and providing improved air quality and aviation warnings, as less fires will be missed.

We simulated MISR and TROPOMI aerosol layer heights (OSSE) from different aerosol profiles to better understand the differences between the two algorithms. The plume heights for profiles with a single aerosol peak agreed almost perfectly and the aerosol layer heights from TROPOMIOSSE and MISR-OSSE were within a just few metres. However, this is not the case for profiles with multiple aerosol layers. From the plume height retrieval using the oxygen $A$ band, the TROPOMI aerosol layer height tends to lie in between those aerosol layers. This is a significant limitation since the plume heights will remain unknown in cases where multiple aerosol layers are present in one profile. MISR on the other hand tends to respond to the upper aerosol layer if multiple plumes overlap the same pixel if there are any layers beneath MISR will not be able to pick this up. However, often multiple layers of plumes do not overlap exactly the exact same area, so MISR will likely sense the lower plume heights over the plume area imaged by the instrument. Based on our OSSE, the different retrieval techniques of TROPOMI and MISR will result in differences of $520 \pm 840 \mathrm{~m}$ (based on 24 profiles), with TROPOMI typically returning lower plume heights. We found a very similar bias when comparing the actual satellite observations; the TROPOMI aerosol layer heights seem to be on average approximately $600 \mathrm{~m}$ lower compared to the MISR plume heights. We further found, by comparing with the CALIOP aerosol profiles, that the TROPOMI aerosol layer heights are more accurate for thicker plumes and over darker surfaces. As such, the difference between the CALIOP and TROPOMI mid-plume height decreases and the correlation increases with increasing plume thickness, and for a $3 \mathrm{~km}$ thick plume the aver- age difference is only about $50 \mathrm{~m}$. Further, the differences between CALIOP and TROPOMI increase with increasing surface albedo. Plumes below $4.5 \mathrm{~km}$ are better retrieved with TROPOMI. However, very high $(>8 \mathrm{~km})$ or thin plumes can be missed by TROPOMI.

The satellite observations have been compared to the GEM-MACH model with input from CFFEPS. From the OSSE, we found that the top altitude with $\mathrm{PM}_{2.5}>$ $10 \mu \mathrm{g} \mathrm{m}^{-3}$ agrees best with the MISR-OSSE ( $\left.-98 \pm 181 \mathrm{~m}\right)$. On the other hand, TROPOMI-OSSE plume heights agree best with the average between the altitude of the maximum and the top altitude with $\mathrm{PM}_{2.5}>10 \mu \mathrm{g} \mathrm{m}^{-3}(37 \pm 90 \mathrm{~m})$. The comparison between the model and the satellite observations shows that the simulated plume heights with CFFEPS tend to be $60-580 \mathrm{~m}$ higher than the observed plume heights by MISR and TROPOMI. The biggest differences between CFFEPS and the TROPOMI observations were found for plumes from grassland fires; CFFEPS overestimates the plume height on average by nearly $1 \mathrm{~km}$. With correlation coefficients between $R=0.28$ and $R=0.73$ between the satellite observations and the model, this is an encouraging result for modelled plume heights, as fire plumes are extremely variable and, as such, difficult to estimate. Many assumptions were made to model the plume injection height.

Overall, TROPOMI aerosol layer height has been compared to MISR and CALIOP plume heights, showing moderate correlation and agreement. The TROPOMI aerosol layer height seems to be successful in retrieving high plumes up to $8 \mathrm{~km}$; the uncertainties seem reduced for thicker and lower plumes between 1 and $4.5 \mathrm{~km}$ altitude, as well as for dark surfaces. TROPOMI aerosol layer height seems to be biased low, this was seen for the comparison to both MISR and CALIOP and is likely due to the tendency of the TROPOMI measurement technique to return an intermediate plume height if multiple aerosol layers are present. Also, the TROPOMI algorithm is sensitive to the surface, which will bias the retrievals low, especially for optically thin plumes (and bright surfaces) (Sanders and de Haan, 2016). Using the oxygen $A$ band to retrieve the aerosol layer has significant limitations if multiple smoke layers are present, leading to an average plume height. This might limit its application for aviation safety as the exact altitude of the plume may be inaccurate. However, it is still a very valuable product if one plume dominates the profile, if model comparison is to be done and for enhancing model performance. The product can also be useful for satellite emission estimates from wildfires, where the approximate layer height of the plume needs to be known to get an accurate wind component of for the plume transport (e.g. Fioletov et al., 2015; Nassar et al., 2017; Adams et al., 2019; Dammers et al., 2019). For these estimates, the aerosol layer height can provide an approximate height of the plume. No significant dependencies of the fire classification, fire radiative power, or the TROPOMI solar and viewing zenith angles towards plume height estimates 
were found within this study; however, more data are needed for a more qualitative comparison.

Data availability. TROPOMI data can be downloaded from https://s5phub.copernicus.eu (last access: 25 March 2020; ESA, 2018); CALIOP data can be downloaded from https://eosweb.larc.nasa.gov/project/calipso/cal_lid_12_05kmlay_ standard_v4_20 (last access: 25 March 2020) (Winker, 2018, https://doi.org/10.5067/CALIOP/CALIPSO/LID_L2_05kmALayStandard-V4-20); NASA Near Real-Time Data and Imagery and MCD14DL MODIS Active Fire Detections (TXT format) are available online at https://earthdata.nasa.gov/active-fire-data (last access: 25 March 2020). The MISR plume heights retrieved with the MINX package (used in this study), and the GEMMACH plume heights can be accessed at http://collaboration. cmc.ec.gc.ca/cmc/arqi/Griffin_et_al_amt-2019-411/ (last access: 25 March 2020; Griffin, 2020).

Supplement. The supplement related to this article is available online at: https://doi.org/10.5194/amt-13-1427-2020-supplement.

Author contributions. DG compiled the analysis; CS performed the observing system simulations; JC, PM, and AA worked on the development of CFFEPS and provided feedback on the methodology used within the paper; MdG, PV, and SN worked on the development of the TROPOMI AER_LH product; ND, AK, and ED helped develop and optimize the analysis codes. The publication was prepared by DG, and all authors reviewed the paper and contributed to the discussion of the paper.

Competing interests. The authors declare that they have no conflict of interest.

Special issue statement. This article is part of the special issue "TROPOMI on Sentinel-5 Precursor: first year in operation (AMT/ACPT inter-journal SI)". It is not associated with a conference.

Acknowledgements. This work contains modified Copernicus Sentinel data. The Sentinel 5 Precursor TROPOMI Level 2 product is developed with funding from the Netherlands Space Office (NSO) and processed with funding from the European Space Agency (ESA). TROPOMI data can be downloaded from https: //s5phub.copernicus.eu (last access: 25 March 2020). The MISR data used in this paper were obtained from the NASA Langley Research Center Atmospheric Science Data Center. Development of the MINX software is supported by NASA Earth Observing System's MISR Project. We would like to thank the MISR project team for making the MINX software available. We acknowledge the use of imagery from the NASA Worldview application (https: //worldview.earthdata.nasa.gov, last access: 25 March 2020), part of the NASA Earth Observing System Data and Information Sys- tem (EOSDIS). The MODIS MCD14DL dataset was provided by LANCE FIRMS operated by NASA ESDIS with funding provided by NASA Headquarters.

Review statement. This paper was edited by Hartmut Boesch and reviewed by three anonymous referees.

\section{References}

Adams, C., McLinden, C. A., Shephard, M. W., Dickson, N., Dammers, E., Chen, J., Makar, P., Cady-Pereira, K. E., Tam, N., Kharol, S. K., Lamsal, L. N., and Krotkov, N. A.: Satellitederived emissions of carbon monoxide, ammonia, and nitrogen dioxide from the 2016 Horse River wildfire in the Fort McMurray area, Atmos. Chem. Phys., 19, 2577-2599, https://doi.org/10.5194/acp-19-2577-2019, 2019.

Akagi, S. K., Yokelson, R. J., Wiedinmyer, C., Alvarado, M. J., Reid, J. S., Karl, T., Crounse, J. D., and Wennberg, P. O.: Emission factors for open and domestic biomass burning for use in atmospheric models, Atmos. Chem. Phys., 11, 4039-4072, https://doi.org/10.5194/acp-11-4039-2011, 2011.

Andreae, M. O.: Emission of trace gases and aerosols from biomass burning - an updated assessment, Atmos. Chem. Phys., 19, 8523-8546, https://doi.org/10.5194/acp-19-8523-2019, 2019.

Anenberg, S. C., Henze, D. K., Tinney, V., Kinney, P. L., Raich, W., Fann, N., Malley, C. S., Roman, H., Lamsal, L., Duncan, B., Martin, R. V., van Donkelaar, A., Brauer, M., Doherty, R., Jonson, J. E., Davila, Y., Sudo, K., and Kuylenstierna, J. C.: Estimates of the global burden of ambient $\mathrm{PM}_{2.5}$, Ozone, and $\mathrm{NO}_{2}$ on asthma incidence and emergency room visits, Environ. Health Persp., 126, 107004, https://doi.org/10.1289/EHP3766, 2018.

Berk, A.: Voigt equivalent widths and spectral-bin singleline transmittances: Exact expansions and the MODTRAN5 implementation, J. Quant. Spectrosc. Ra., 118, 102-120, https://doi.org/10.1016/j.jqsrt.2012.11.026, 2013.

Byram, G. M.: Combustion of forest fuels, in: Forest fire: control and use, edited by: Davis, K. P., McGraw-Hill, New York, NY, USA, 61-89, available at: https://www.frames.gov/catalog/9652 (last access: 1 August 2018), 1959.

Chen, J., Anderson, K., Pavlovic, R., Moran, M. D., Englefield, P., Thompson, D. K., Munoz-Alpizar, R., and Landry, H.: The FireWork v2.0 air quality forecast system with biomass burning emissions from the Canadian Forest Fire Emissions Prediction System v2.03, Geosci. Model Dev., 12, 3283-3310, https://doi.org/10.5194/gmd-12-3283-2019, 2019.

Colarco, P. R., Schoeberl, M. R., Doddridge, B. G., Marufu, L. T., Torres, O., and Welton, E. J.: Transport of smoke from Canadian forest fires to the surface near Washington, D.C.: Injection height, entrainment, and optical properties, J. Geophys. Res.Atmos., 109, D06203, https://doi.org/10.1029/2003JD004248, 2004.

Côté, J., Gravel, S., Méthot, A., Patoine, A., Roch, M., and Staniforth, A.: The Operational CMC-MRB Global Environmental Multiscale (GEM) Model. Part I: Design Considerations and Formulation, Mon. Weather Rev., 126, 1373-1395, https://doi.org/10.1175/15200493(1998)126<1373:TOCMGE>2.0.CO;2, 1998. 
Dammers, E., McLinden, C. A., Griffin, D., Shephard, M. W., Van Der Graaf, S., Lutsch, E., Schaap, M., Gainairu-Matz, Y., Fioletov, V., Van Damme, M., Whitburn, S., Clarisse, L., CadyPereira, K., Clerbaux, C., Coheur, P. F., and Erisman, J. W.: $\mathrm{NH}_{3}$ emissions from large point sources derived from CrIS and IASI satellite observations, Atmos. Chem. Phys., 19, 12261-12293, https://doi.org/10.5194/acp-19-12261-2019, 2019.

Damoah, R., Spichtinger, N., Forster, C., James, P., Mattis, I., Wandinger, U., Beirle, S., Wagner, T., and Stohl, A.: Around the world in 17 days - hemispheric-scale transport of forest fire smoke from Russia in May 2003, Atmos. Chem. Phys., 4, 13111321, https://doi.org/10.5194/acp-4-1311-2004, 2004.

Derwent, R., Stevenson, D., Collins, W., and Johnson, C.: Intercontinental transport and the origins of the ozone observed at surface sites in Europe, Atmos. Environ., 38, 1891-1901, https://doi.org/10.1016/j.atmosenv.2004.01.008, 2004.

Diner, D. J., Asner, G. P., Davies, R., Knyazikhin, Y., Muller, J.-P., Nolin, A. W., Pinty, B., Schaaf, C. B., and Stroeve, J.: New Directions in Earth Observing: Scientific Applications of Multiangle Remote Sensing, B. Am. Meteorol. Soc., 80, 2209-2228, https://doi.org/10.1175/15200477(1999)080<2209:NDIEOS>2.0.CO;2, 1999.

Duck, T. J., Firanski, B. J., Millet, D. B., Goldstein, A. H., Allan, J., Holzinger, R., Worsnop, D. R., White, A. B., Stohl, A., Dickinson, C. S., and van Donkelaar, A.: Transport of forest fire emissions from Alaska and the Yukon Territory to Nova Scotia during summer 2004, J. Geophys. Res.-Atmos., 112, D10S44, https://doi.org/10.1029/2006JD007716, 2007.

ESA: Sentinel-5P Pre-Operations Data Hub, available at: https:// s5phub.copernicus.eu/dhus (last access: 25 March 2020), 2018.

Fioletov, V. E., McLinden, C. A., Krotkov, N., and Li, C.: Lifetimes and emissions of $\mathrm{SO}_{2}$ from point sources estimated from OMI, Geophys. Res. Let., 42, 1969-1976, https://doi.org/10.1002/2015GL063148, 2015.

Fisher, D., Muller, J., and Yershov, V. N.: Automated Stereo Retrieval of Smoke Plume Injection Heights and Retrieval of Smoke Plume Masks From AATSR and Their Assessment With CALIPSO and MISR, IEEE T. Geosci. Remote S., 52, 12491258, https://doi.org/10.1109/TGRS.2013.2249073, 2014.

Giglio, L., Descloitres, J., Justice, C. O., and Kaufman, Y. J.: An Enhanced Contextual Fire Detection Algorithm for MODIS, Remote Sens. Environ., 87, 273-282, https://doi.org/10.1016/S0034-4257(03)00184-6, 2003.

Giglio, L., Csiszar, I., and Justice, C. O.: Global distribution and seasonality of active fires as observed with the Terra and Aqua Moderate Resolution Imaging Spectroradiometer (MODIS) sensors, J. Geophys. Res.-Biogeo., 111, G02016, https://doi.org/10.1029/2005JG000142, 2006.

Giglio, L., Schroeder, W., and Justice, C. O.: The collection 6 MODIS active fire detection algorithm and fire products, Remote Sens. Environ., 178, 31-41, https://doi.org/10.1016/j.rse.2016.02.054, 2016.

Girard, C., Plante, A., Desgagné, M., McTaggart-Cowan, R., Côté, J., Charron, M., Gravel, S., Lee, V., Patoine, A., Qaddouri, A., Roch, M., Spacek, L., Tanguay, M., Vaillancourt, P. A., and Zadra, A.: Staggered Vertical Discretization of the Canadian Environmental Multiscale (GEM) Model Using a Coordinate of the Log-Hydrostatic-Pressure Type, Mon. Weather Rev., 142, 11831196, https://doi.org/10.1175/MWR-D-13-00255.1, 2014.
Gonzalez-Alonso, L., Val Martin, M., and Kahn, R. A. Biomass-burning smoke heights over the Amazon observed from space, Atmos. Chem. Phys., 19, 1685-1702, https://doi.org/10.5194/acp-19-1685-2019, 2019.

Griffin, D.: MISR MINX and GEM-MACH plume heights [Data set], Environment and Climate Change Canada, available at: https://collaboration.cmc.ec.gc.ca/cmc/arqi/Griffin_et_ al_amt-2019-411/, last access: 25 March 2020.

Hansen, J. E. and Travis, L. D.: Light scattering in planetary atmospheres, Space Sci. Rev., 16, 527-610, https://doi.org/10.1007/BF00168069, 1974.

Jaffe, D., Bertschi, I., Jaeglé, L., Novelli, P., Reid, J. S., Tanimoto, H., Vingarzan, R., and Westphal, D. L.: Long-range transport of Siberian biomass burning emissions and impact on surface ozone in western North America, Geophys. Res. Lett., 31, L16106, https://doi.org/10.1029/2004GL020093, 2004.

Kahn, R. A., Li, W.-H., Moroney, C., Diner, D. J., Martonchik, J. V., and Fishbein, E.: Aerosol source plume physical characteristics from space-based multiangle imaging, J. Geophys. Res.-Atmos., 112, D11205, https://doi.org/10.1029/2006JD007647, 2007.

Kahn, R. A., Chen, Y., Nelson, D. L., Leung, F.-Y., Li, Q., Diner, D. J., and Logan, J. A.: Wildfire smoke injection heights: Two perspectives from space, Geophys. Res. Lett., 35, L04809, https://doi.org/10.1029/2007GL032165, 2008.

Kim, S.-W., Berthier, S., Raut, J.-C., Chazette, P., Dulac, F., and Yoon, S.-C.: Validation of aerosol and cloud layer structures from the space-borne lidar CALIOP using a ground-based lidar in Seoul, Korea, Atmos. Chem. Phys., 8, 3705-3720, https://doi.org/10.5194/acp-8-3705-2008, 2008.

Kitzberger, T., Brown, P. M., Heyerdahl, E. K., Swetnam, T. W., and Veblen, T. T.: Contingent Pacific-Atlantic Ocean influence on multicentury wildfire synchrony over western North America, P. Natl. Acad. Sci. USA, 104, 543-548, https://doi.org/10.1073/pnas.0606078104, 2007.

Kou, L.: Atmospheric measurements and radiative effect, $\mathrm{PhD}$ thesis, Dalhousie University, Halifax, Canada, 1996.

Landis, M., Edgerton, E., White, E., Wentworth, G., Sullivan, A., and Dillner, A.: The impact of the 2016 Fort McMurray Horse River Wildfire on ambient air pollution levels in the Athabasca Oil Sands Region, Alberta, Canada, Sci. Total Environ., 618, 1665-1676, https://doi.org/10.1016/j.scitotenv.2017.10.008, 2018.

Lee, B. S., Alexander, M. E., Hawkes, B. C., Lynham, T. J., Stocks, B. J., and Englefield, P.: Information systems in support of wildland fire management decision making in Canada, Comput. Electron. Agr., 37, 185-198, 2002.

Littell, J. S., McKenzie, D., Peterson, D. L., and Westerling, A. L.: Climate and wildfire area burned in western U.S. ecoprovinces, 1916-2003, Ecol. Appl., 19, 1003-1021, https://doi.org/10.1890/07-1183.1, 2009.

Lutsch, E., Dammers, E., Conway, S., and Strong, K.: Longrange transport of $\mathrm{NH}_{3}, \mathrm{CO}, \mathrm{HCN}$, and $\mathrm{C}_{2} \mathrm{H}_{6}$ from the 2014 Canadian Wildfires, Geophys. Res. Lett., 43, 8286-8297, https://doi.org/10.1002/2016GL070114, 2016.

Lutsch, E., Strong, K., Jones, D. B. A., Ortega, I., Hannigan, J. W., Dammers, E., Shephard, M. W., Morris, E., Murphy, K., Evans, M. J., Parrington, M., Whitburn, S., Van Damme, M., Clarisse, L., Coheur, P.-F., Clerbaux, C., Croft, B., Martin, R. V., Pierce, J. R., and Fisher, J. A.: Unprecedented Atmospheric Ammo- 
nia Concentrations Detected in the High Arctic From the 2017 Canadian Wildfires, J. Geophys. Res.-Atmos., 124, 8178-8202, https://doi.org/10.1029/2019JD030419, 2019.

Lyapustin, A., Wang, Y., Korkin, S., Kahn, R., and Winker, D.: MAIAC Thermal Technique for Smoke Injection Height From MODIS, IEEE Geosci. Remote Sens. Lett., published online, 15, https://doi.org/10.1109/LGRS.2019.2936332, 2019.

Makar, P., Gong, W., Hogrefe, C., Zhang, Y., Curci, G., Z̆abkar, R., Milbrandt, J., Im, U., Balzarini, A., Baró, R., Bianconi, R., Cheung, P., Forkel, R., Gravel, S., Hirtl, M., Honzak, L., Hou, A., Jiménez-Guerrero, P., Langer, M., Moran, M., Pabla, B., Pérez, J., Pirovano, G., José, R. S., Tuccella, P., Werhahn, J., Zhang, J., and Galmarini, S.: Feedbacks between air pollution and weather, part 2: Effects on chemistry, Atmos. Environ., 115, 499-526, https://doi.org/10.1016/j.atmosenv.2014.10.021, 2015a.

Makar, P., Gong, W. F., Milbrandt, J., Hogrefe, C., Zhang, Y., Curci, G., Žabkar, R., Im, U., Balzarini, A., Baró, R., Bianconi, R., Cheung, P., Forkel, R., Gravel, S., Hirtl, M., Honzak, L., Hou, A., Jimenez-Guerrero, P., Langer, M., and Galmarini, S.: Feedbacks between air pollution and weather, Part 1: Effects on weather, Atmos. Environ., 115, 442-469, https://doi.org/10.1016/j.atmosenv.2014.12.003, 2015b.

McGill, M. J., Vaughan, M. A., Trepte, C. R., Hart, W. D., Hlavka, D. L., Winker, D. M., and Kuehn, R.: Airborne validation of spatial properties measured by the CALIPSO lidar, J. Geophys. Res.-Atmos., 112, D20201, https://doi.org/10.1029/2007JD008768, 2007.

McLinden, C. A., McConnell, J. C., Griffioen, E., and McElroy, C. T.: A vector radiative-transfer model for the Odin/OSIRIS project, Can. J. Phys., 80, 375-393, https://doi.org/10.1139/p01156, 2002.

Meng, J., Martin, R. V., Li, C., van Donkelaar, A., TzompaSosa, Z. A., Yue, X., Xu, J.-W., Weagle, C. L., and Burnett, R. T.: Source Contributions to Ambient Fine Particulate Matter for Canada, Environ. Sci. Technol., 17, 10269-10278, https://doi.org/10.1021/acs.est.9b02461, 2019.

Moran, M. D., Ménard, S., Talbot, D., Huang, P., Makar, P. A., Gong, W., Landry, H., Gravel, S., Gong, S., Crevier, L.-P., Kallaur, A., and Sassi, M.: Particulate-matter forecasting with GEM-MACH15, a new Canadian air-quality forecast model, in: Air Pollution Modelling and Its Application XX, Springer, Dordrecht, the Netherlands, 2010.

Moroney, C., Davies, R., and Muller, J.: Operational retrieval of cloud-top heights using MISR data, IEEE T. Geosci. Remote, 40, 1532-1540, https://doi.org/10.1109/TGRS.2002.801150, 2002.

Muller, J. ., Mandanayake, A., Moroney, C., Davies, R., Diner, D. J., and Paradise, S.: MISR stereoscopic image matchers: techniques and results, IEEE T. Geosci. Remote., 40, 1547-1559, https://doi.org/10.1109/TGRS.2002.801160, 2002.

Munoz-Alpizar, R., Pavlovic, R., Moran, M. D., Chen, J., Gravel, S., Henderson, S. B., Ménard, S., Racine, J., Duhamel, A., Gilbert, S., Beaulieu, P.-A., Landry, H., Davignon, D., Cousineau, S., and Bouchet, V.: Multi-Year (2013-2016) PM $_{2.5}$ Wildfire Pollution Exposure over North America as Determined from Operational Air Quality Forecasts, Atmosphere, 8, 179, https://doi.org/10.3390/atmos8090179, 2017.

Nanda, S., de Graaf, M., Veefkind, J. P., ter Linden, M., Sneep, M., de Haan, J., and Levelt, P. F.: A neural network radiative transfer model approach applied to the Tropospheric Monitoring Instru- ment aerosol height algorithm, Atmos. Meas. Tech., 12, 66196634, https://doi.org/10.5194/amt-12-6619-2019, 2019.

Nassar, R., Hill, T. G., McLinden, C. A., Wunch, D., Jones, D. B. A., and Crisp, D.: Quantifying $\mathrm{CO}_{2}$ Emissions From Individual Power Plants From Space, Geophys. Res. Lett., 44, 1004510053, https://doi.org/10.1002/2017GL074702, 2017.

Naud, C., Muller, J.-P., Haeffelin, M., Morille, Y., and Delaval, A.: Assessment of MISR and MODIS cloud top heights through inter-comparison with a backscattering lidar at SIRTA, Geophys. Res. Lett., 31, L04114, https://doi.org/10.1029/2003GL018976, 2004.

Nelson, D. L., Chen, Y., Kahn, R. A., Diner, D. J., and Mazzoni, D.: Example applications of the MISR INteractive eXplorer (MINX) software tool to wildfire smoke plume analyses, Proc. SPIE 7089, Remote Sensing of Fire: Science and Application, 708909, https://doi.org/10.1117/12.795087, 2008.

Nelson, D. L., Garay, M. J., Kahn, R. A., and Dunst, B. A.: Stereoscopic Height and Wind Retrievals for Aerosol Plumes with the MISR INteractive eXplorer (MINX), Remote Sensing, 5, 45934628, https://doi.org/10.3390/rs5094593, 2013.

Omar, A. H., Winker, D. M., Vaughan, M. A., Hu, Y., Trepte, C. R., Ferrare, R. A., Lee, K.-P., Hostetler, C. A., Kittaka, C., Rogers, R. R., Kuehn, R. E., and Liu, Z.: The CALIPSO Automated Aerosol Classification and Lidar Ratio Selection Algorithm, J. Atmos. Ocean. Tech., 26, 1994-2014, https://doi.org/10.1175/2009JTECHA1231.1, 2009.

Pavlovic, R., Chen, J., Anderson, K., Moran, M. D., Beaulieu, P.A., Davignon, D., and Cousineau, S.: The FireWork air quality forecast system with near-real-time biomass burning emissions: Recent developments and evaluation of performance for the 2015 North American wildfire season, J. Air Waste Manage. Assoc., 66, 819-841, https://doi.org/10.1080/10962247.2016.1158214, 2016.

Pendlebury, D., Gravel, S., Moran, M. D., and Lupu, A.: Impact of chemical lateral boundary conditions in a regional air quality forecast model on surface ozone predictions during stratospheric intrusions, Atmos. Environ., 174, 148-170, https://doi.org/10.1016/j.atmosenv.2017.10.052, 2018.

Raffuse, S. M., Craig, K. J., Larkin, N. K., Strand, T. T., Sullivan, D. C., Wheeler, N. J. M., and Solomon, R.: An Evaluation of Modeled Plume Injection Height with SatelliteDerived Observed Plume Height, Atmosphere, 3, 103-123, https://doi.org/10.3390/atmos3010103, 2012.

Reid, J. S. and Hobbs, P. V.: Physical and optical properties of young smoke from individual biomass fires in Brazil, J. Geophys. Res.Atmos., 103, 32013-32030, https://doi.org/10.1029/98JD00159, 1998.

Sanders, A. F. J. and de Haan, J. F.: TROPOMI ATBD of the Aerosol Layer Height product, available at: http://www.tropomi. eu/sites/default/files/files/S5P-KNMI-L2-0006-RP-TROPOMI_ ATBD_Aerosol_Height-v1p0p0-20160129.pdf (last access: 25 March 2020), 2016.

Schraufnagel, D. E., Balmes, J. R., Cowl, C. T., Matteis, S. D., Jung, S.-H., Mortimer, K., Perez-Padilla, R., Rice, M. B., Riojas-Rodriguez, H., Sood, A., Thurston, G. D., To, T., Vanker, A., and Wuebbles, D. J.: Air Pollution and Noncommunicable Diseases: A Review by the Forum of International Respiratory Societies' Environmental Committee, Part 1: 
The Damaging Effects of Air Pollution, Chest, 155, 409-416, https://doi.org/10.1016/j.chest.2018.10.042, 2019.

Tao, Z., McCormick, M., and Wu, D.: A comparison method for spaceborne and ground-based lidar and its application to the CALIPSO lidar, Appl. Phys. B, 91, 639, https://doi.org/10.1007/s00340-008-3043-1, 2008.

Teakles, A. D., So, R., Ainslie, B., Nissen, R., Schiller, C., Vingarzan, R., McKendry, I., Macdonald, A. M., Jaffe, D. A., Bertram, A. K., Strawbridge, K. B., Leaitch, W. R., Hanna, S., Toom, D., Baik, J., and Huang, L.: Impacts of the July 2012 Siberian fire plume on air quality in the Pacific Northwest, Atmos. Chem. Phys., 17, 2593-2611, https://doi.org/10.5194/acp17-2593-2017, 2017.

Tosca, M. G., Randerson, J. T., Zender, C. S., Nelson, D. L., Diner, D. J., and Logan, J. A.: Dynamics of fire plumes and smoke clouds associated with peat and deforestation fires in Indonesia, J. Geophys. Res.-Atmos., 116, D08207, https://doi.org/10.1029/2010JD015148, 2011.

Val Martin, M., Logan, J. A., Kahn, R. A., Leung, F.-Y., Nelson, D. L., and Diner, D. J.: Smoke injection heights from fires in North America: analysis of 5 years of satellite observations, Atmos. Chem. Phys., 10, 1491-1510, https://doi.org/10.5194/acp10-1491-2010, 2010.

Val Martin, M., Kahn, R. A., and Tosca, M. G.: A Global Analysis of Wildfire Smoke Injection Heights Derived from Space-Based Multi-Angle Imaging, Remote Sensing, 10, 1609, https://doi.org/10.3390/rs10101609, 2018.

Vaughan, M. A., Powell, K. A., Winker, D. M., Hostetler, C. A., Kuehn, R. E., Hunt, W. H., Getzewich, B. J., Young, S. A., Liu, Z., and McGill, M. J.: Fully Automated Detection of Cloud and Aerosol Layers in the CALIPSO Lidar Measurements, J. Atmos. Ocean. Tech., 26, 2034-2050, https://doi.org/10.1175/2009JTECHA1228.1, 2009.

Veefkind, J., Aben, I., McMullan, K., Forster, H., de Vries, J., Otter, G., Claas, J., Eskes, H., de Haan, J., Kleipool, Q., van Weele, M., Hasekamp, O., Hoogeveen, R., Landgraf, J., Snel, R., Tol, P., Ingmann, P., Voors, R., Kruizinga, B., Vink, R., Visser, H., and Levelt, P.: TROPOMI on the ESA Sentinel-5 Precursor: A GMES mission for global observations of the atmospheric composition for climate, air quality and ozone layer applications, Remote Sens. Environ., 120, 70-83, https://doi.org/10.1016/j.rse.2011.09.027, 2012.
Westerling, A. L.: Increasing western US forest wildfire activity: sensitivity to changes in the timing of spring, Philos. T. R. Soc. B, 371, 20150178, https://doi.org/10.1098/rstb.2015.0178, 2016.

Winker, D.: CALIPSO Lidar Level $25 \mathrm{~km}$ Aerosol Layer Data V420 [Data set], NASA Langley Atmospheric Science Data Center DAAC, https://doi.org/10.5067/caliop/calipso/lid_12_05kmalaystandard-v4-20, 2018.

Winker, D. M., Pelon, J. R., and McCormick, M. P.: CALIPSO mission: spaceborne lidar for observation of aerosols and clouds, Proc. SPIE 4893, Lidar Remote Sensing for Industry and Environment Monitoring III, https://doi.org/10.1117/12.466539, 2003.

Winker, D. M., Hunt, W. H., and McGill, M. J.: Initial performance assessment of CALIOP, Geophys. Res. Lett., 34, L19803, https://doi.org/10.1029/2007GL030135, 2007.

Xu, X., Wang, J., Wang, Y., Zeng, J., Torres, O., Yang, Y., Marshak, A., Reid, J., and Miller, S.: Passive remote sensing of altitude and optical depth of dust plumes using the oxygen $\mathrm{A}$ and $\mathrm{B}$ bands: First results from EPIC/DSCOVR at Lagrange-1 point, Geophys. Res. Lett., 44, 7544-7554, https://doi.org/10.1002/2017GL073939, 2017.

Xu, X., Wang, J., Wang, Y., Zeng, J., Torres, O., Reid, J. S., Miller, S. D., Martins, J. V., and Remer, L. A.: Detecting layer height of smoke aerosols over vegetated land and water surfaces via oxygen absorption bands: hourly results from EPIC/DSCOVR in deep space, Atmos. Meas. Tech., 12, 32693288, https://doi.org/10.5194/amt-12-3269-2019, 2019.

Yue, X., Mickley, L. J., Logan, J. A., Hudman, R. C., Martin, M. V., and Yantosca, R. M.: Impact of 2050 climate change on North American wildfire: consequences for ozone air quality, Atmos. Chem. Phys., 15, 10033-10055, https://doi.org/10.5194/acp-1510033-2015, 2015.

Zakšek, K., Hort, M., Zaletelj, J., and Langmann, B.: Monitoring volcanic ash cloud top height through simultaneous retrieval of optical data from polar orbiting and geostationary satellites, Atmos. Chem. Phys., 13, 2589-2606, https://doi.org/10.5194/acp13-2589-2013, 2013. 